\title{
A REINFORCED CONCRETE \\ BUILDING IN WELLINGTON
}

J. P. Hollings*

\section{Introduction}

The building which is to be studied is an apartment building on a one acre site in Wellington's oriental Bay. It was a design and build venture of Wilkins and Davies Development Co. Ltd. Registered Architects were employed for the design and the author's firm as consulting engineers with normal professional responsibilities for design and supervision of the structure and of the site works. In order to achieve the best financial return on the venture the maximum possible number of flats had to be fitted on to the site. With the town planning requirements for separation distance and the need for adequate car parking, this meant a tall building with 15 floors of flats ( 4 and 5 flats per floor) over a ground floor of parking.

\section{Selection of Structural Type}

The construction company favoured a slip form core with a lift slab floor system and the design shown in Fig. I was prepared to test this.
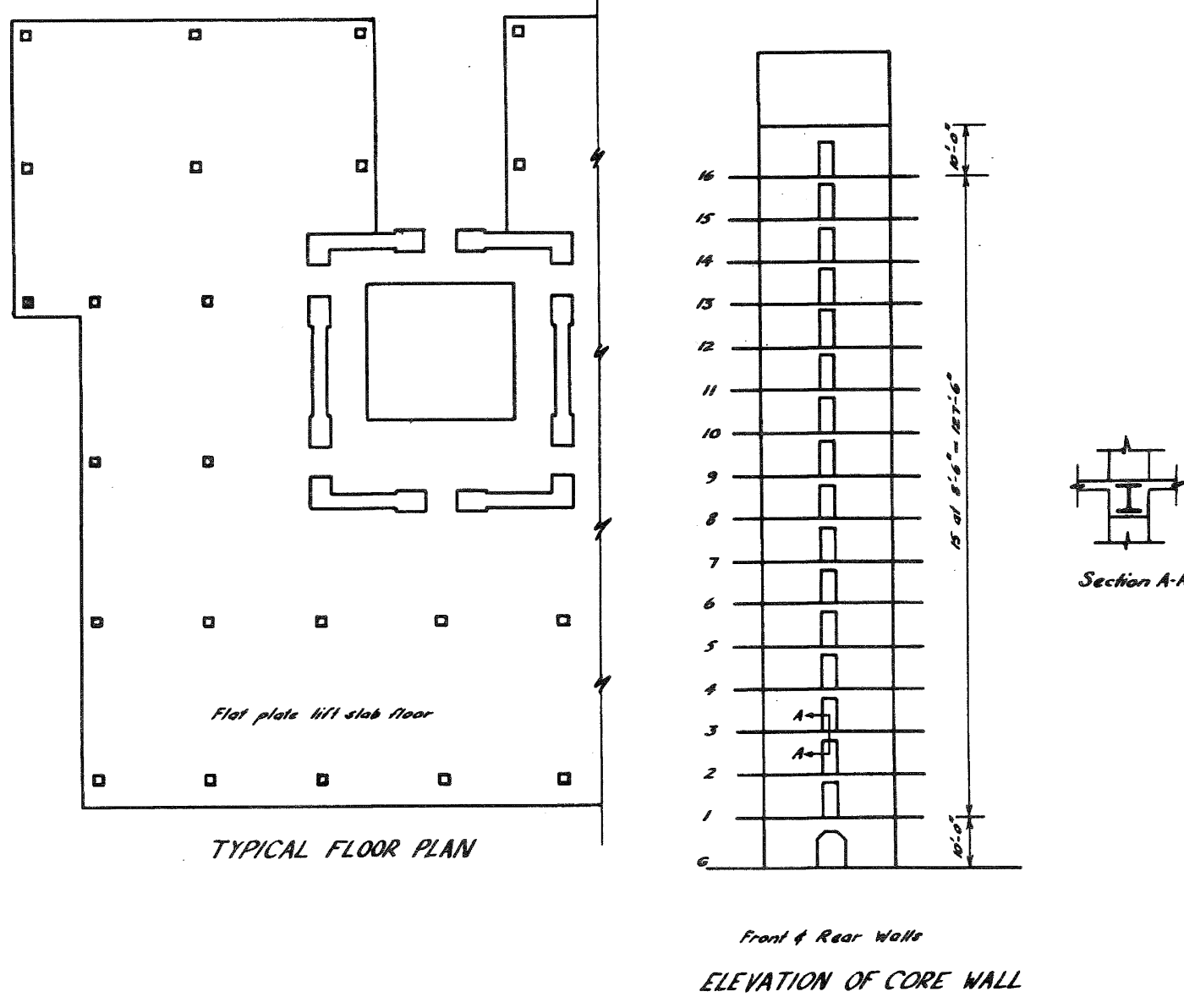

Section A-A throygh door head

ELEVATION OF CORE WALL

Fig. 1 A Trial Design Type

*Partner, Beca Carter Hollings \& Ferner, Consulting Engineers, Wellington 
When this was compared with the selected design it was found to cost (estimate) approximately $\$ 100,000.00$ more due mainly to the extra foundation cost required to stabilise the tall narrow tower against overturning. Difficulties of analysis around the tower openings, of ductility of the tower, of torsional stiffness and of adequate earthquake connections of the lift slabs all favoured the selected design.

This is shown in Figs. 2 and 3.

Fig. 2 .

The Completed

Apartment

Building.
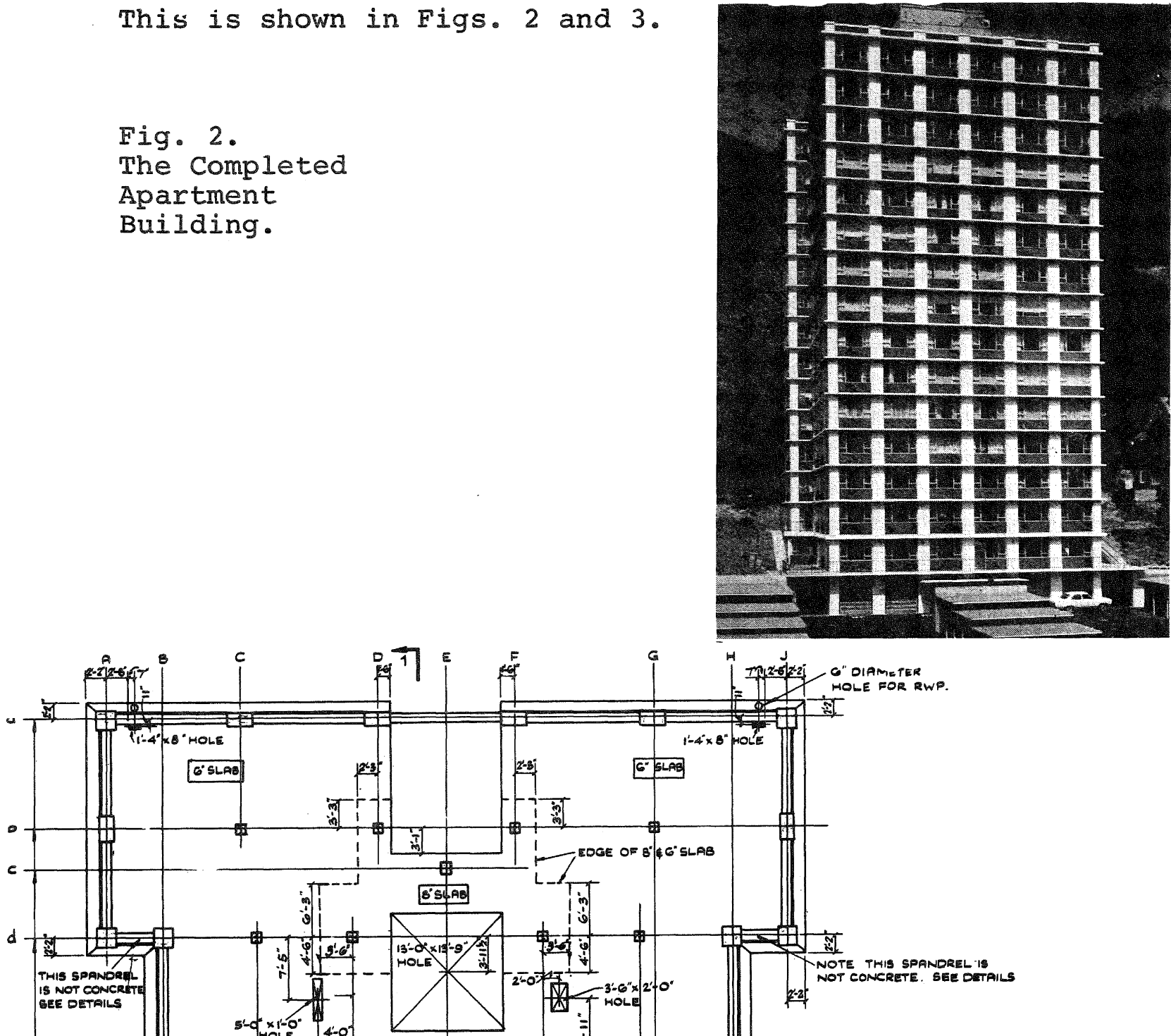

Fig. 3.

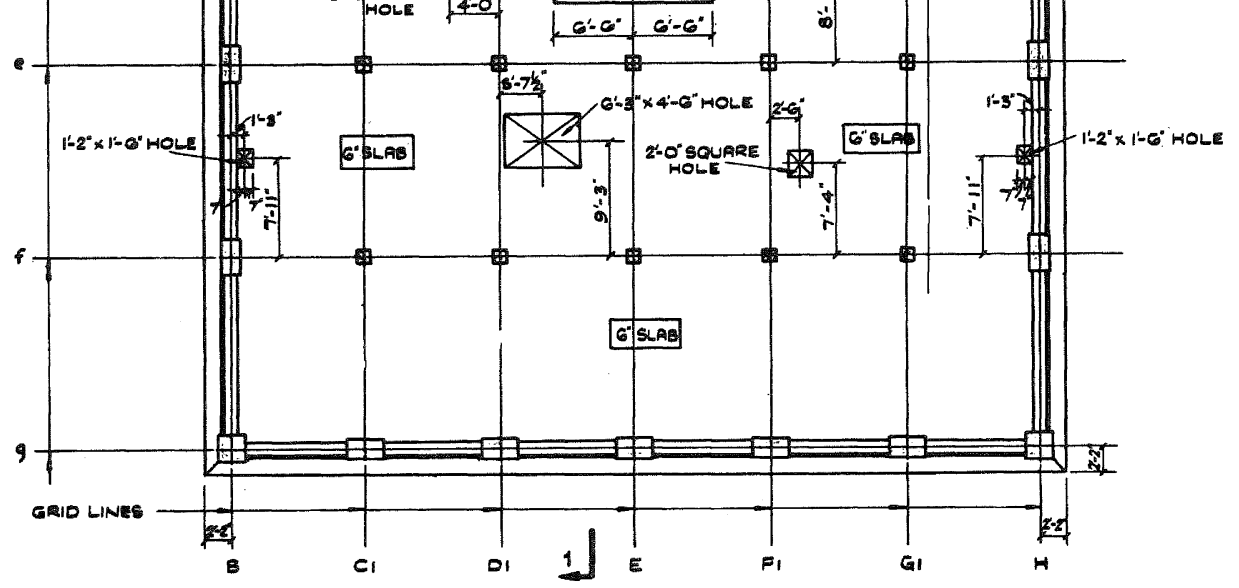


It consists of beamless flat plate floors (in order to get the maximum number of floors within the town planning height limit) and for the necessary earthquake resistance a strong frame system is provided all round the perimeter of the building. Floors are 6 " thick generally; internal columns 14" x 14"; external or face columns $36^{\prime \prime} \times 20 "$ and corner columns 28" $\times 28^{\prime \prime}$. Beam sizes in the external frames are 36" deep (including the 6" slab hung from the beam base) and varying in width 16", 14" and 12" up the building. 5000 p.s.i. concrete was used for the internal columns; $4000 \mathrm{p} . \mathrm{s.i}$. for the beams and elsewhere concrete was 3500 p.s.i. High tensile reinforcing of 60,000 p.s.i. yield (HY60) was used throughout.

\section{Codes}

The main design decisions were made in early 1964 when Wellington city did not have a settled high building structural policy, nor was the N.Z.S.S. 1900 Chapter 8 available. Initial design was done using the SEAOC code with W.C.C. approval but this was later changed to the N.Z.S.S. 1900 Chapter 8 code levels as soon as this code came out in draft form. Fig. 4 shows that this decision more than doubled the design loads (in the short period range).

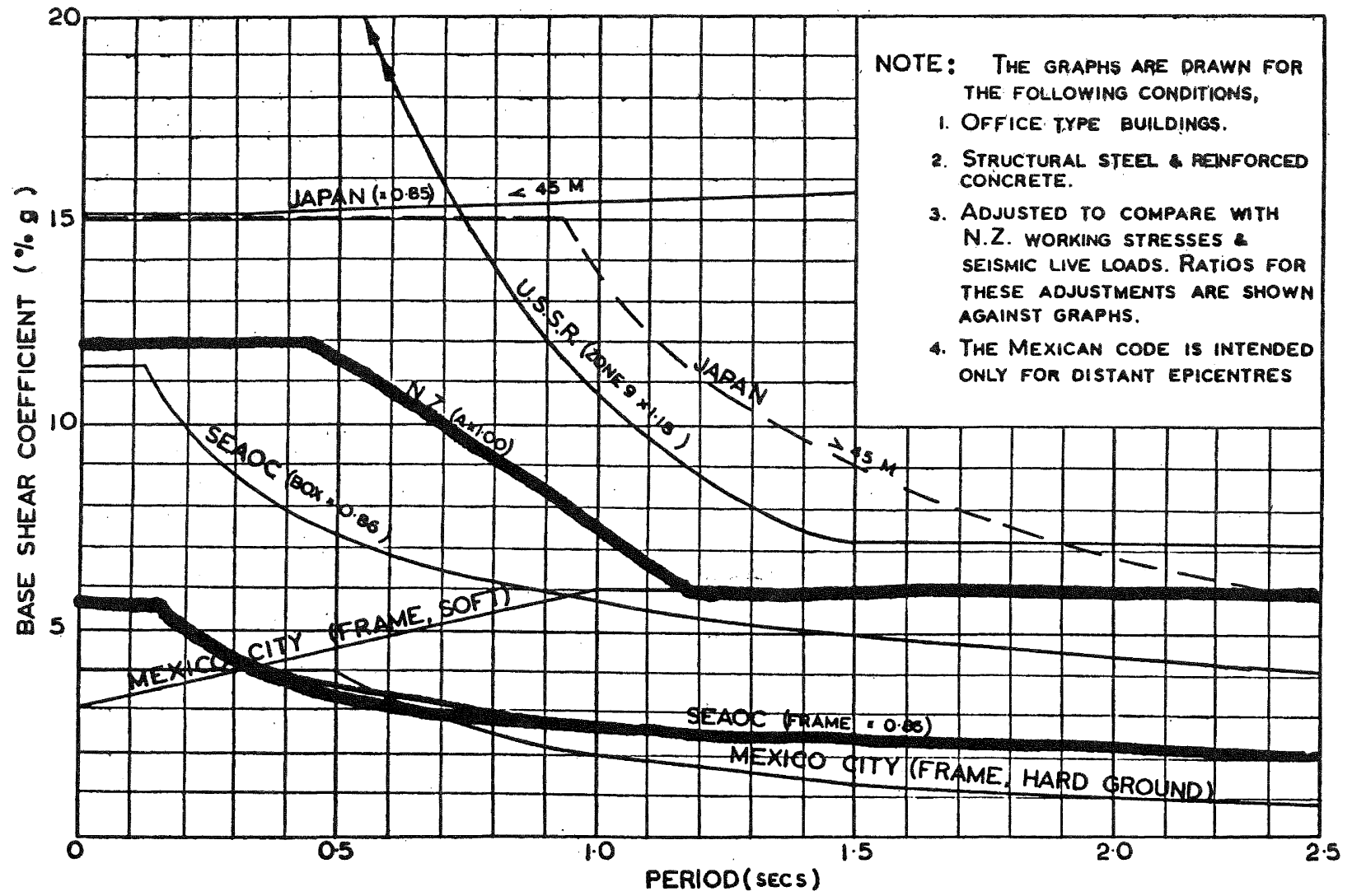

Fig.4 Comparison of Basic Coefficients. 
While there are strong arguments for the use of SEAOC code strength levels as a national policy, it is unwise for one developer to use SEAOC loads. This is solely because his structures would have a higher level of structural damage in a major earthquake.

\section{STATIC ANALYSIS}

The time allowed for design was short and a rapid yet reliable design technique was necessary. The system used to obtain frames with properly distributed strength and with ductility where needed as described in my previous lecture will now be outlined for comparison with a full elasto-plastic dynamic analysis later performed by Messrs Shepherd and Walpole.

While it would have been desirable to have a long period structure on the rock foundation of this site, to achieve this would have required a careful balance between strength and natural period with possibly several trials and consequent loss of time. Instead a stiff structure was accepted, the necessary additional strength being obtained economically through the use of deep structural members.

A satisfactory manual static analysis based on the code would have to be capable of:

(i) Sharing out the code loads between frames;

(ii) Providing elastic deflections for period checking;

(iii) Allowing for provision to be made for torsion;

(iv) Providing moments, shears, axial loads directly for design.

The text book method of achieving aim (i) is to use a floor by floor comparison over the building height. A more reliable method is to compare the deflected shapes over the full height of the building of the various structural resisting elements under unit applied static loads; this done, one can make manual estimated adjustments for compatibility between these building elements. This technique will now be illustrated.

Fig. 4a. shows half of one frame of the building under a static triangular lateral load. If the frame members are correctly proportioned (as this one is) then such methods as the modified portal analysis method (Sutherland and Bowman) allow moments and shears to be written down directly on this sheet with confidence that they are correct within a few per cent.

With the aid of a few simplifying assumptions we can now devise formulae for that portion of frame deflection which is due individually to girder rotations, column flexure, girder shear, column shear, cantilever action (column direct extension or compression) pile strains, and soil compressibility. If these formulae are tabulated a simple computation as in Fig. 5 for the frame analysed in Fig. 4 gives a complete picture of this frame's deflections under the Fig. 4a. loads. 


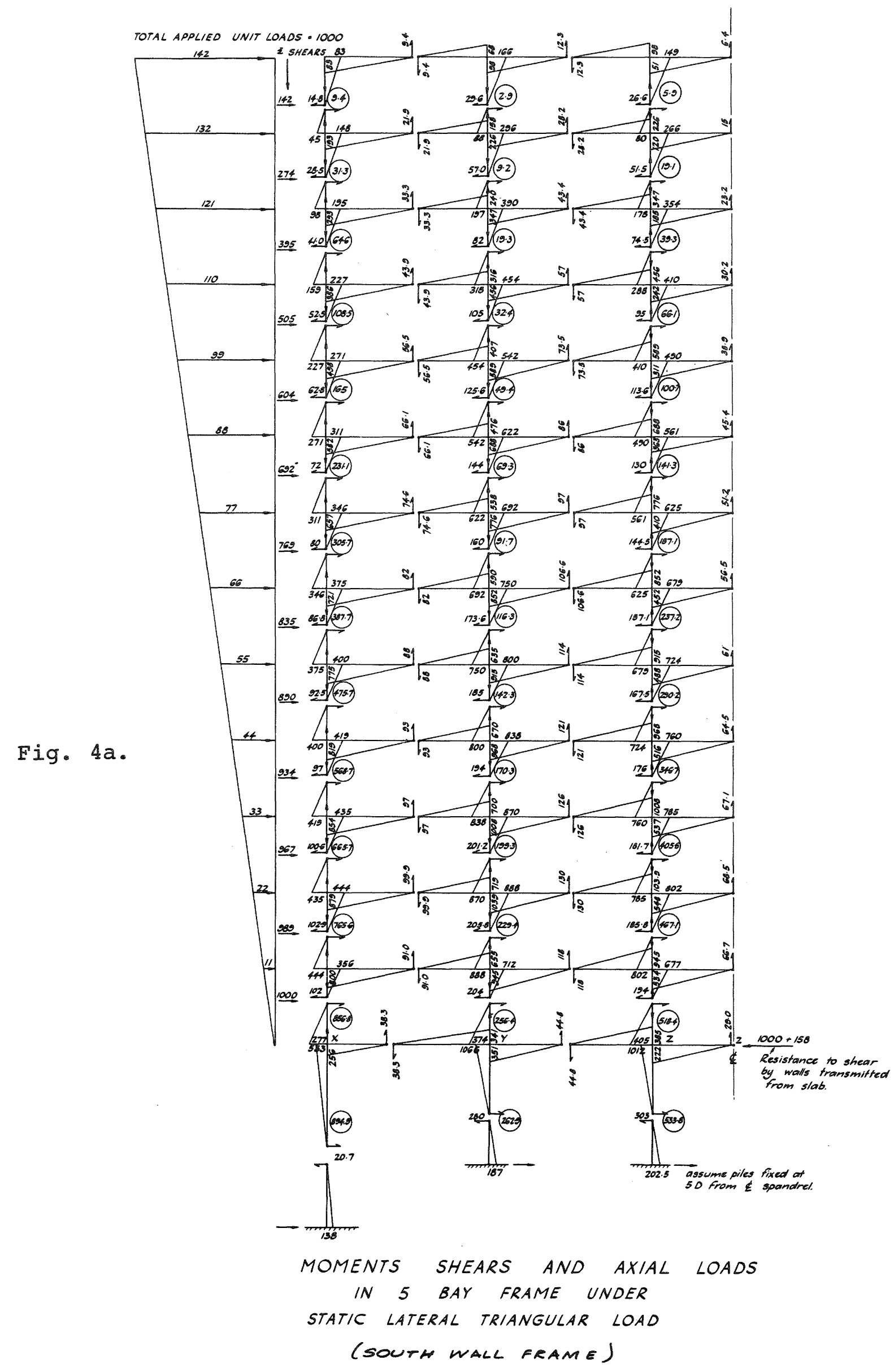



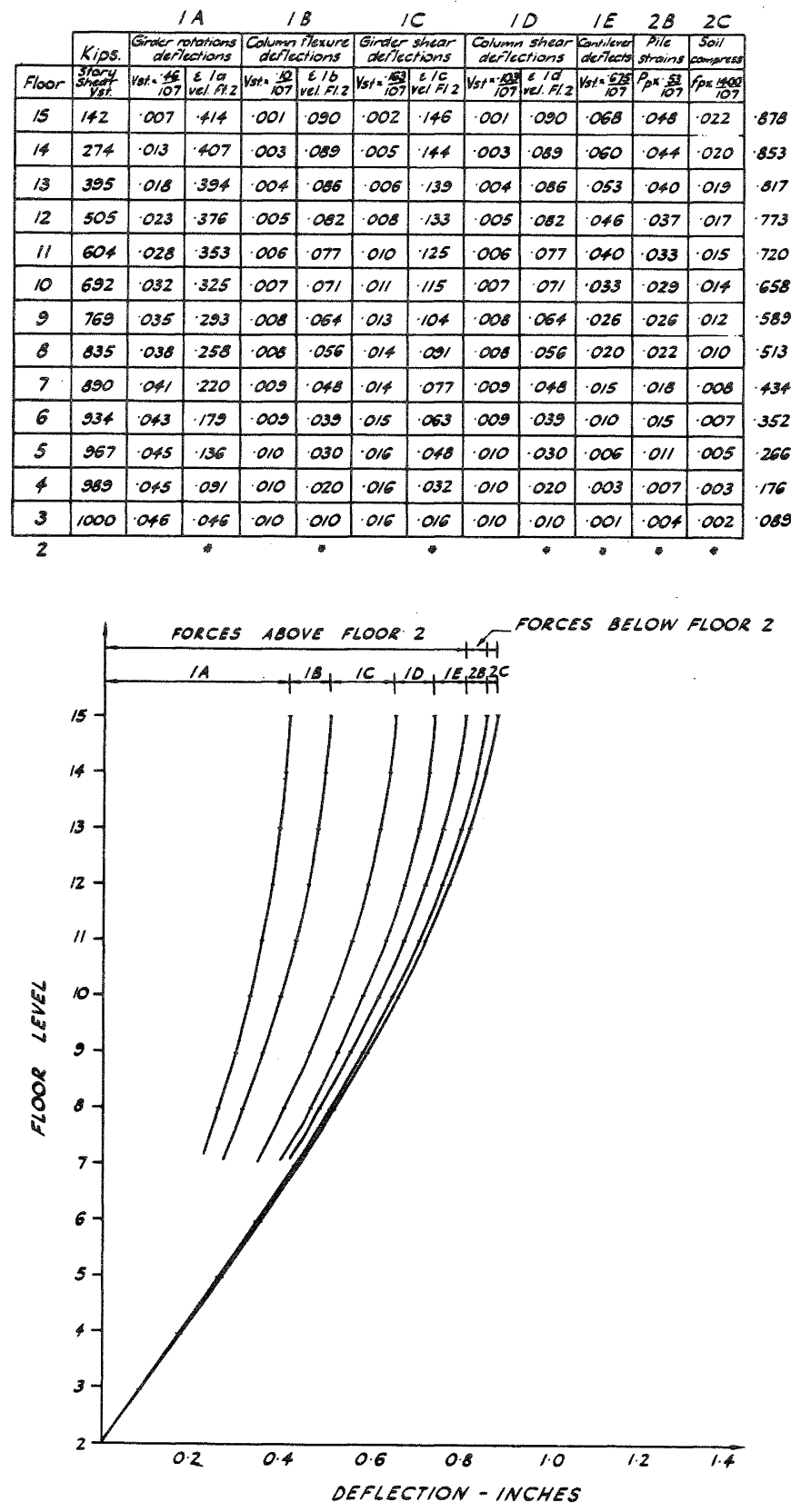

Fig. 5
TOTAL DEFLECTIONS

OF

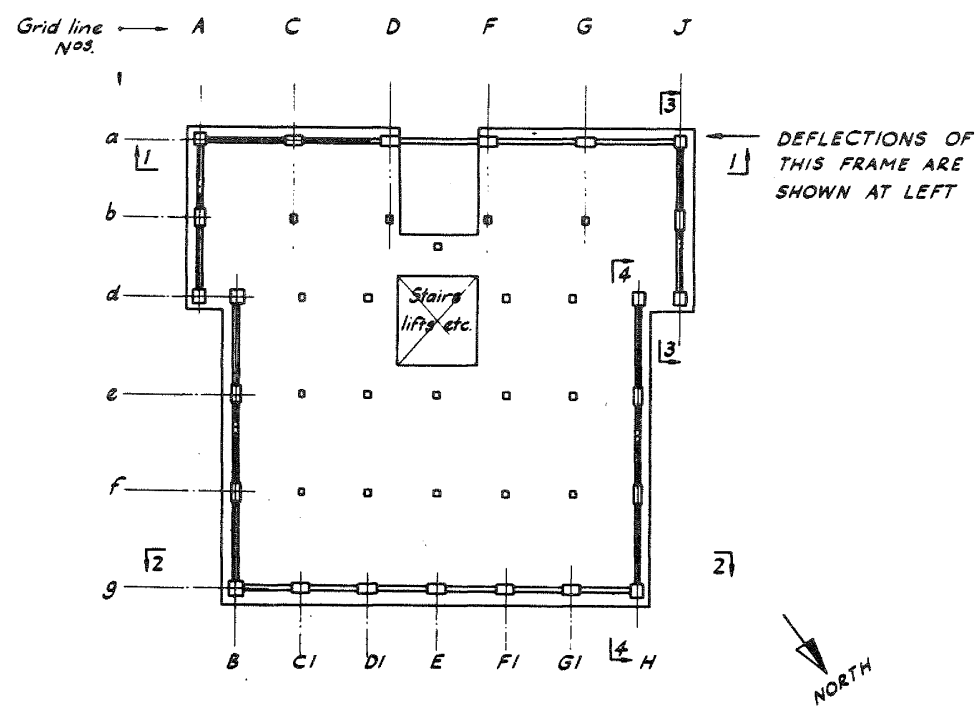

KEY PLAN OF SPANDREL BEAM LAYOUT Typical for floors 3.15 inclusive.

\section{FRAME Aa-Ja UNDER STATIC $\angle O A D$}

When this operation has been carried out for each frame of the building (including the interior "bents" represented by a strip of floor slab taken with the exterior columns) a diagram such as that of Fig. 6 may be plotted. In this figure the deflected shape of each frame has been factored so that deflections are equal to the 12 th floor. It is seen that. percentage variations at other floors are negligible. This means in effect that we may share out the total static load on the building between all the frames using the stiffness relations established in Fig. 5 and in such a way that 12 th floor deflections are equal. This gives reliable answers and also allows one to make some rational allowance for torsion if desired. 


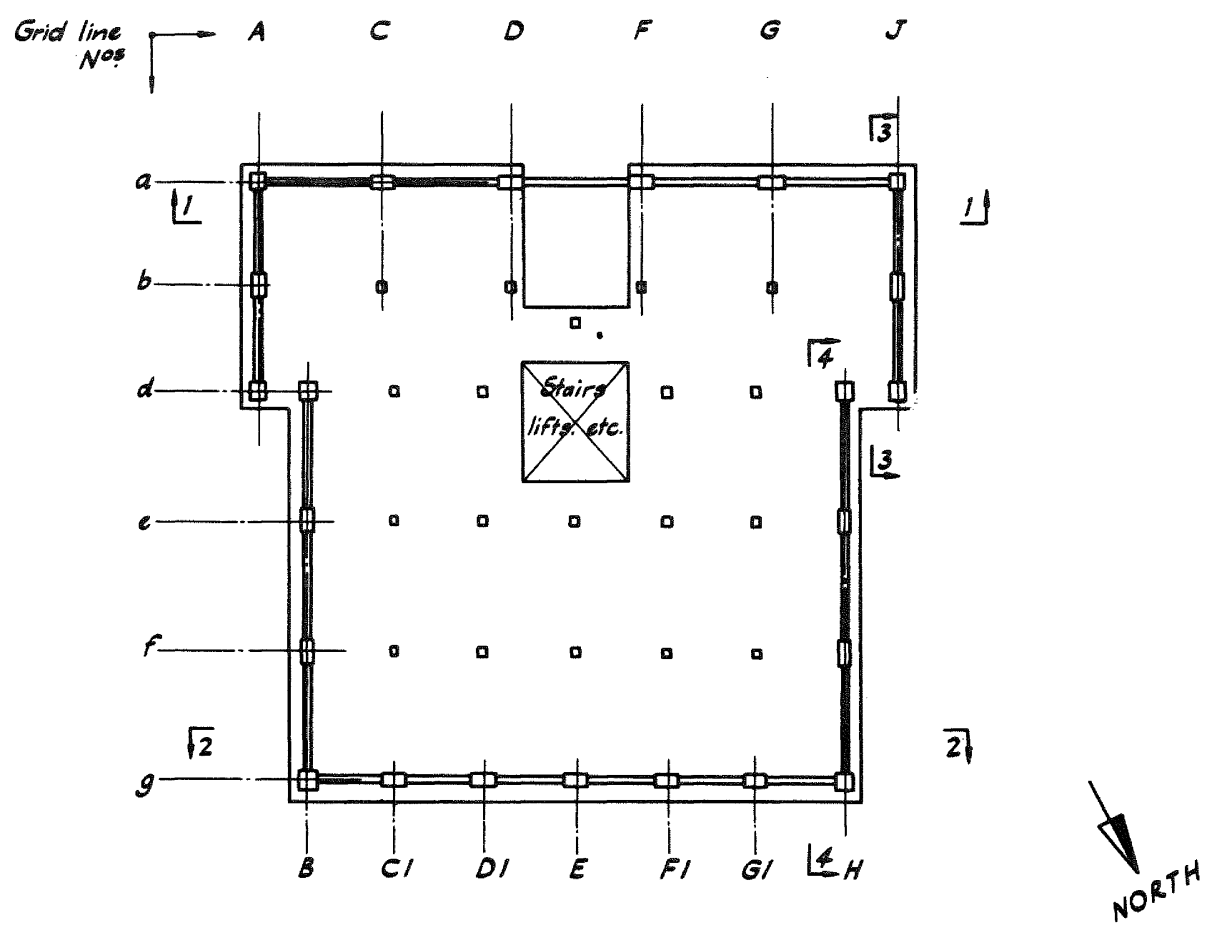

KEY PLAN OF SPANDREL BEAM LAYOUT

Typical for floors 3-15 inclusive

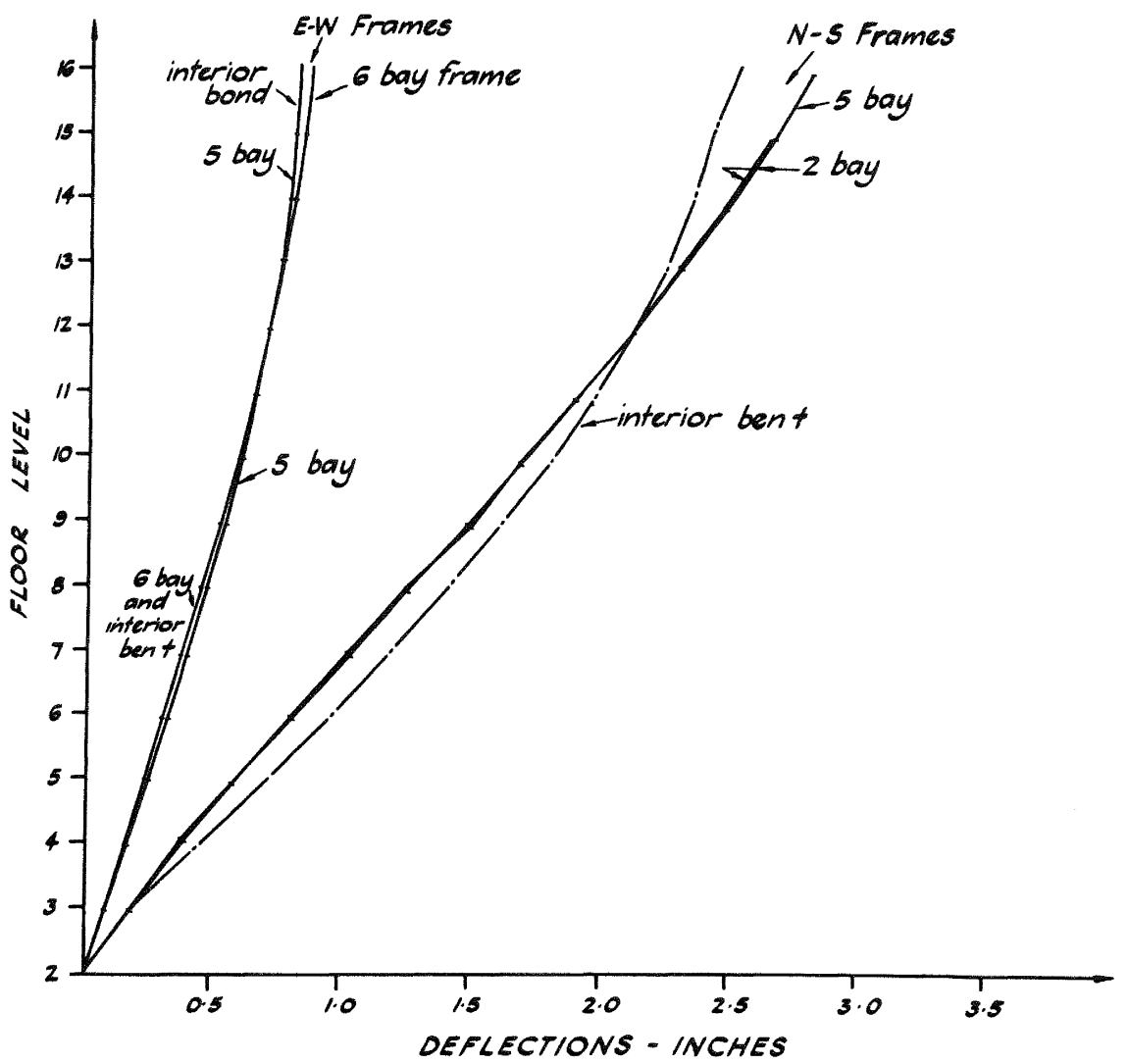

As deflection shapes compare well for a common deflection at Floor 12, assume that relative frame constants are obtained from a comparison of the frame deflections at floor 12.

Fig. 6 Plot of Deflected Shapes of Frames Under Static Triangular Load. 
It is interesting to note in passing that for this particular structure $92 \%$ of the total lateral load is taken by the external wall frames and only 8\% by the internal "bents" made up of slab and internal columns.

From the deflection calculations such as Fig. 5 the natural period of the building may now be calculated using the code formula $\mathrm{T}=0.32 \sqrt{\mathrm{D}}$.

This gave periods of 0.58 seconds east-west and 0.77 north-south, and from the graphs in Fig. 4 base shear coefficients of $0.11 \mathrm{~g}$. and 0.95 may be read off. The coefficients used in design were 0.12 and 0.10 corresponding to periods of 0.45 and 0.7 seconds. Later computer dynamic analyses completed by Mr Shepherd of the University of Canterbury towards the closing phases of the design gave natural periods very close to these figures.

Knowing the total base shear and how it is distributed to the various frames, calculations such as that of Fig. $4 \mathrm{a}$. based on unit loads may now be adjusted by simple proportion to give a complete picture of moments shears and axial forces throughout the structure.

\section{General Ductility Provisions}

The calculations described so far correspond to Phase I of my previous paper. In Phase II (ductility) it will be remembered we should find where the plastic hinges will form; design the hinges; and finally check the structure between the hinges. These operations will now be described.

Where Will The Plastic Hinges Form? At the time this structure was designed full elasto-plastic dynamic analyses were not available so one of the expedients outlined in my previous paper had to be resorted to and it was decided to attempt to force all the plastic hinging to occur in the beam ends. This was done by:

(i) Matching the beam strengths to the elastic diagram as closely as possible. A uniform load factor of 1.45 was selected to bring all the beams to yield from the code load level.

(ii) Giving the columns as large a margin as possible over the elastic strengths required by the code levels of loading. A factor of 1.25 over the beam strengths was set as a minimum but more was provided where economically possible. Thus as a minimum the columns have an ultimate strength of $1.45 \times 1.25$ times the code strength levels.

The actual charts used in design are shown in Fig. 7. Column sizes are standard at 28" $\times 28^{\prime \prime}$ for corner columns and $36^{\prime \prime} \times 20$ "for face columns and main column reinforcing was standardised at either 8,12 , 16 or 24 bars of $1 \frac{1}{4} "$ dia. HY60. With these standards load moment interaction curves can be drawn for each standard column and it is these curves which are plotted as the full lines of Fig. 7 . 

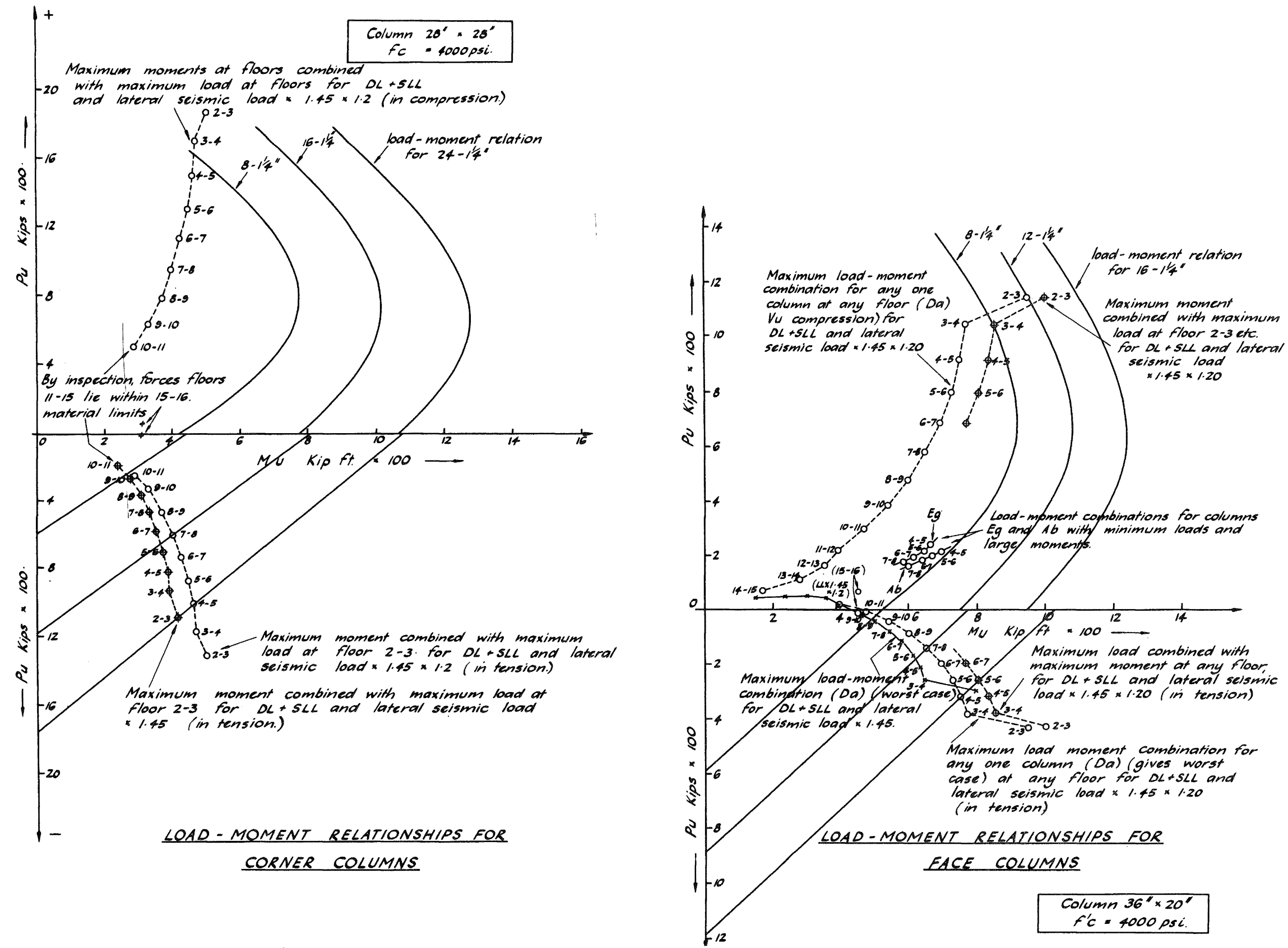

Fig. 7 Design of main Frame Columns Above Floor 2

(1a selection of main reinforcing) 
On these interaction diagrams are also plotted the worst load moment combinations obtained from the $1.45 \times 1.25$ criterion above (circles joined by dashed lines). In general the minima set can be easily met except on the tension plus moment of the diagram where in the lower floors the maximum steel provided is insufficient. This was thought to be nevertheless satisfactory since tension yielding of column steel under these conditions is not a loss of ductility and to provide more steel would have been uneconomic.

Design of the Plastic Hinges. The design of the beam hinges is a direct illustration of the principles set out in my previous paper. Because the hinges are equally reinforced top and bottom and the concrete compression zones have been provided with binding steel, and because also the beams are short and deep, the hinge rotations are limited by permissible steel strains not by permissible concrete strains.

Fig. 8 shows the stress-strain curve for HY60 steel. A load factor of 1.25 was selected as a minimum safe value against steel rupture due to hinge rotation and on this basis $2 \frac{1}{2} \%$ is the limiting allowable steel strain.

In Fig. 9 the results of applying this to a typical beam are illustrated. The moment diagram shows how if steel strain hardening is taken into account an estimate of the plastic length may be made from first principles. From the strain diagram then and using the formulae quoted in my previous paper an available safe plastic hinge rotation of 0.01 radians may be obtained. Note the very modest concrete strains at the top of the compression steel.

Fig. 10 plots beam moment against top of building deflection and on the equal energy criterion outlined in my previous paper 0.01 beam hinge rotation corresponds to 17 inches deflection or an earthquake of 1.2 times the severity of the El Centro shaking.

Design of Structure Between the Hinges. Throughout this design a basic aim was to achieve economy in the use of reinforcing by keeping main longitudinal bars in beams especially, but also in columns, to a minimum. This is the same as saying the total lateral strength of the building should be kept down as far as possible. At the same time a high degree of earthquake resistance was sought through careful detailing for ductility and one of the prime effects of this is the need for generous use of secondary reinforcing (i.e. binding and shear steel).

In the beams the criterion of full plastic hinges of opposite sign at each end of the beams was used; ordinary vertical load beam shear and torsional shear from the slabs was also allowed for. In addition a small load factor was applied to cover strain hardening of the main reinforcing at the hinges with the consequential rise in the hinge moment capacities. 


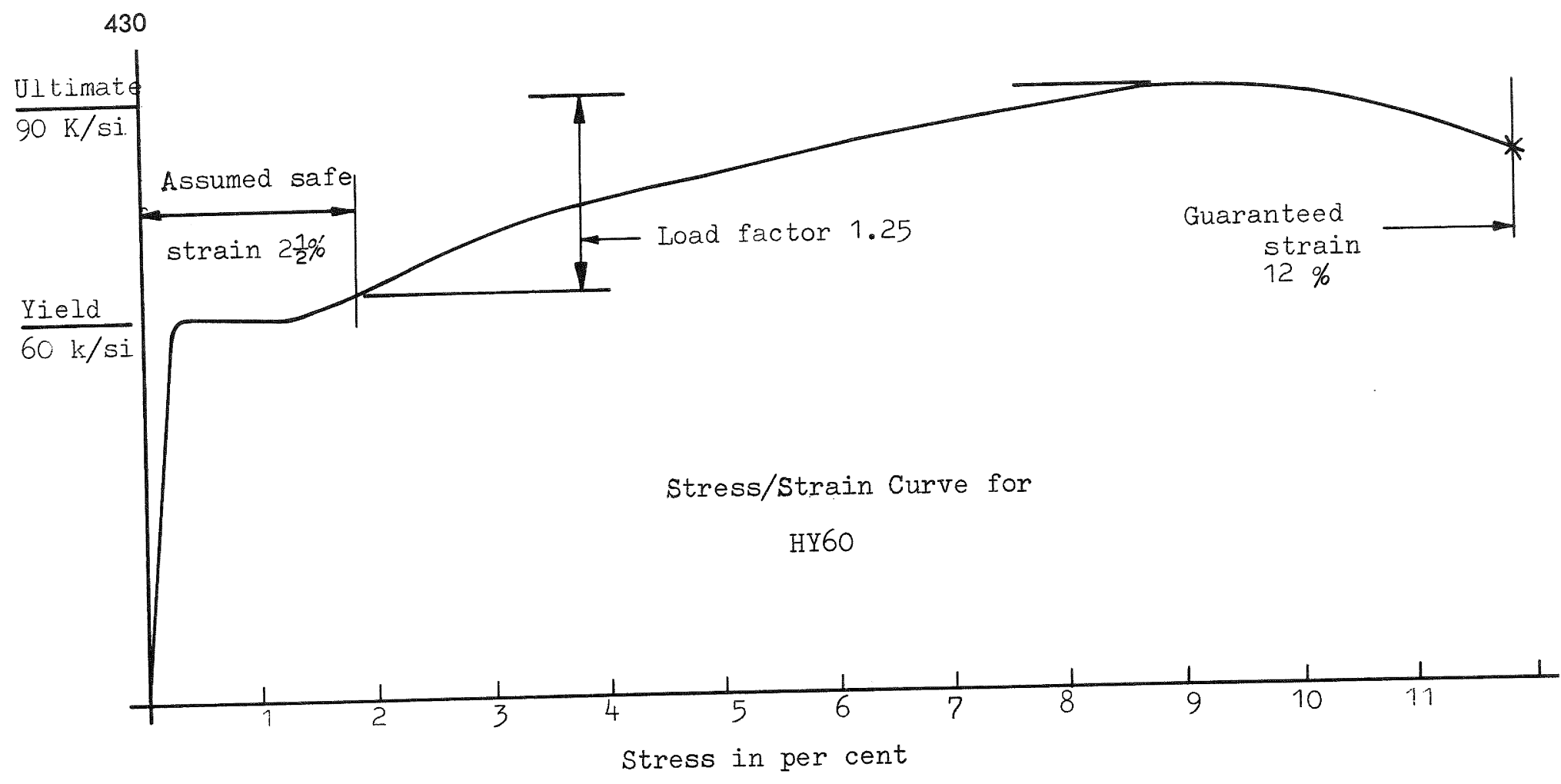

Fig. 8 Selection of Safe Design Strain for HY60 Reinforcing.

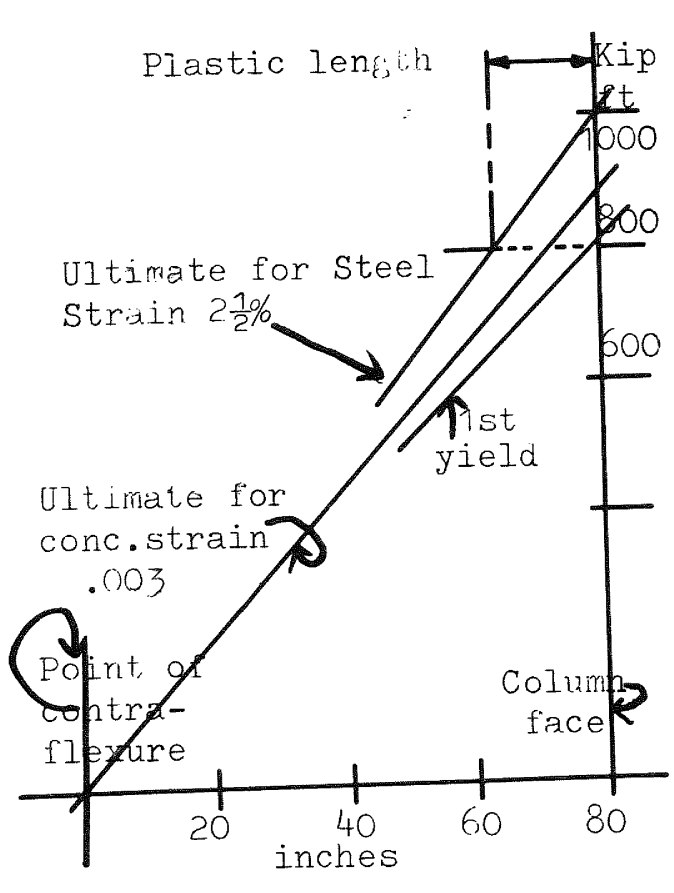

Moment Diagram

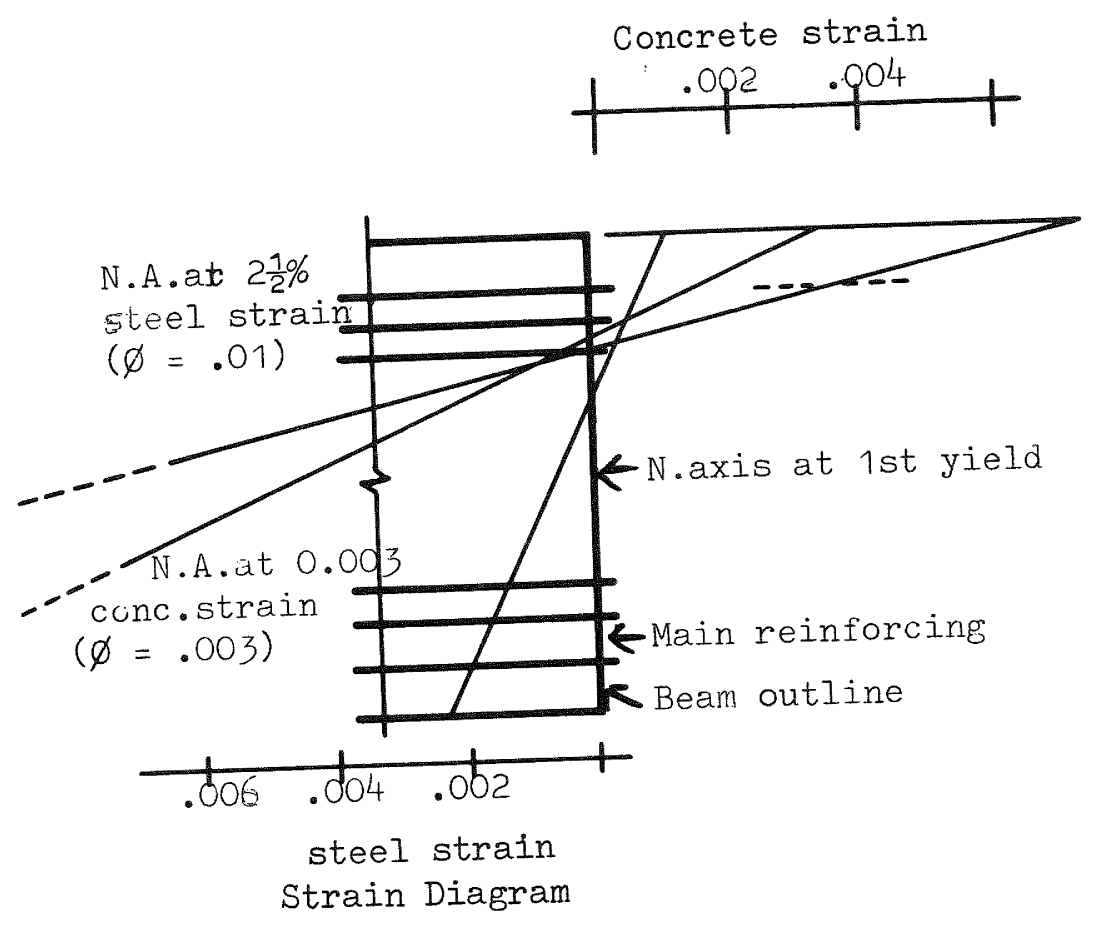

Concrete strain

Fig. 9 Calculation of Plastic Hinge Rotation. 


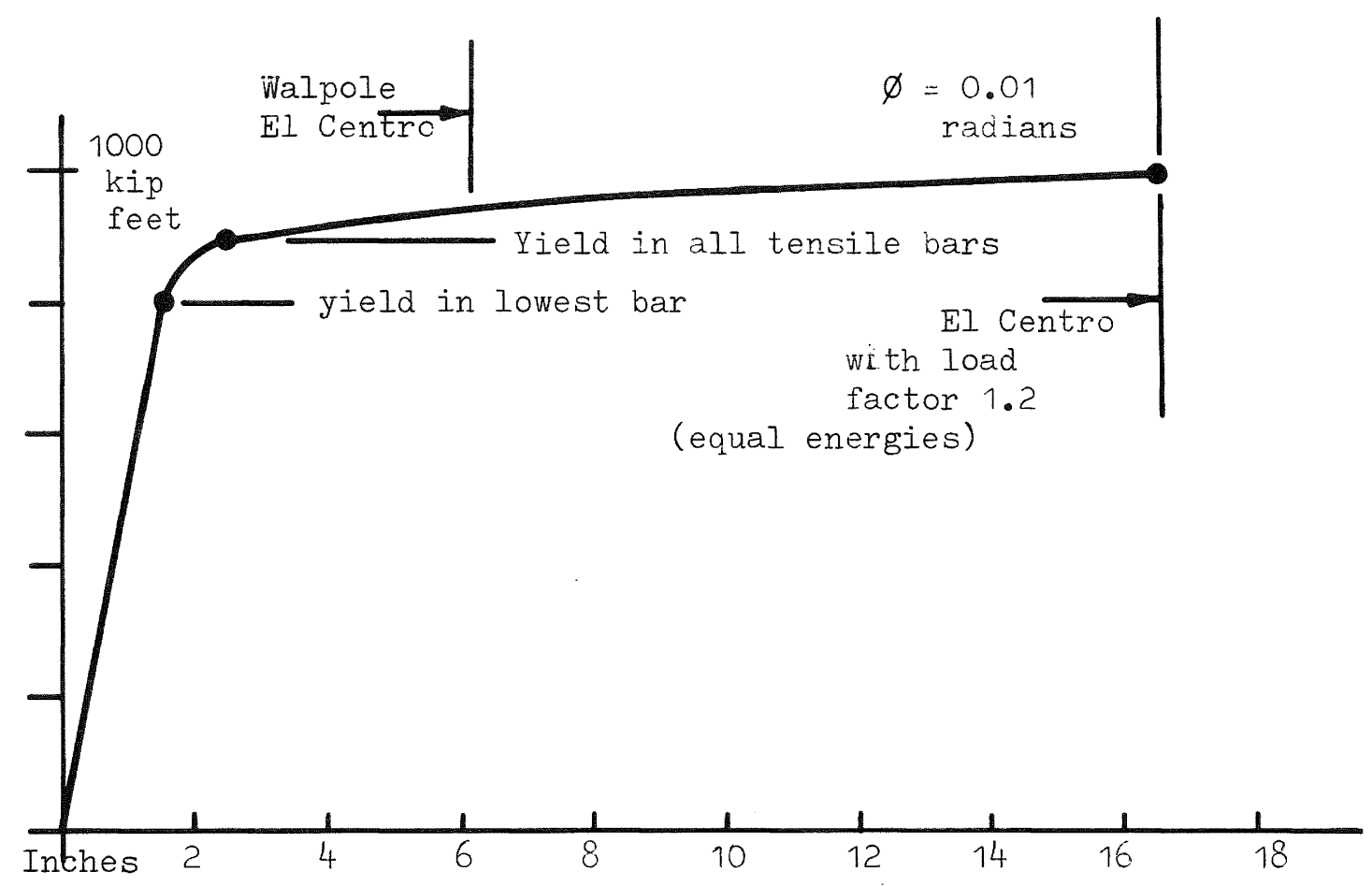

Fig. 10 Beam Moment Plotted Against Building Deflection.

Selection of the appropriate shear steel for the columns was more difficult. The need to maintain the integrity of the columns as load bearing units holding the floors apart whatever the earthquake, was regarded as paramount. The possibility of hinges of reversed sign at top and bottom of each column (i.e. in external walls) was ruled out because of the attempts to keep hinges out of columns. Nevertheless, the possibility of hinging in the columns in responses to second or third mode vibrations had to be borne in mind. For this reason a minimum column binding steel at the Blume Newmark and Corning level (easily met with $0.01 \%$ ) was provided everywhere and this steel also functioned as shear steel. An absolute minimum for shear steel based on shears corresponding to the full beam hinging condition factored by 1.1 for beam steel strain hardening and by a further 1.5 as a margin was provided. Wherever possible steel in excess of this to meet the Blume Newmark and Corning recommendations for columns was also provided. These provisions are illustrated in Fig. 11 which is reproduced directly from the design calculations.

The many detail problems associated with the design of the structure between the hinges to secure ductility cannot be covered fully in the time available but some will be mentioned later under detailing.

\section{Comparison of Ductility Provisions with Full Elasto-Plastic Analysis Results}

Some time after the design work had been completed Warren Walpole, working for a $\mathrm{Ph} . \mathrm{D}$. under $\mathrm{Mr}$ Shepherd of the University of Canterbury, carried out an elasto-plastic analysis of one frame of this structure. This work is of very great interest because it gives a means of checking reliably the ductility provisions made during design. 


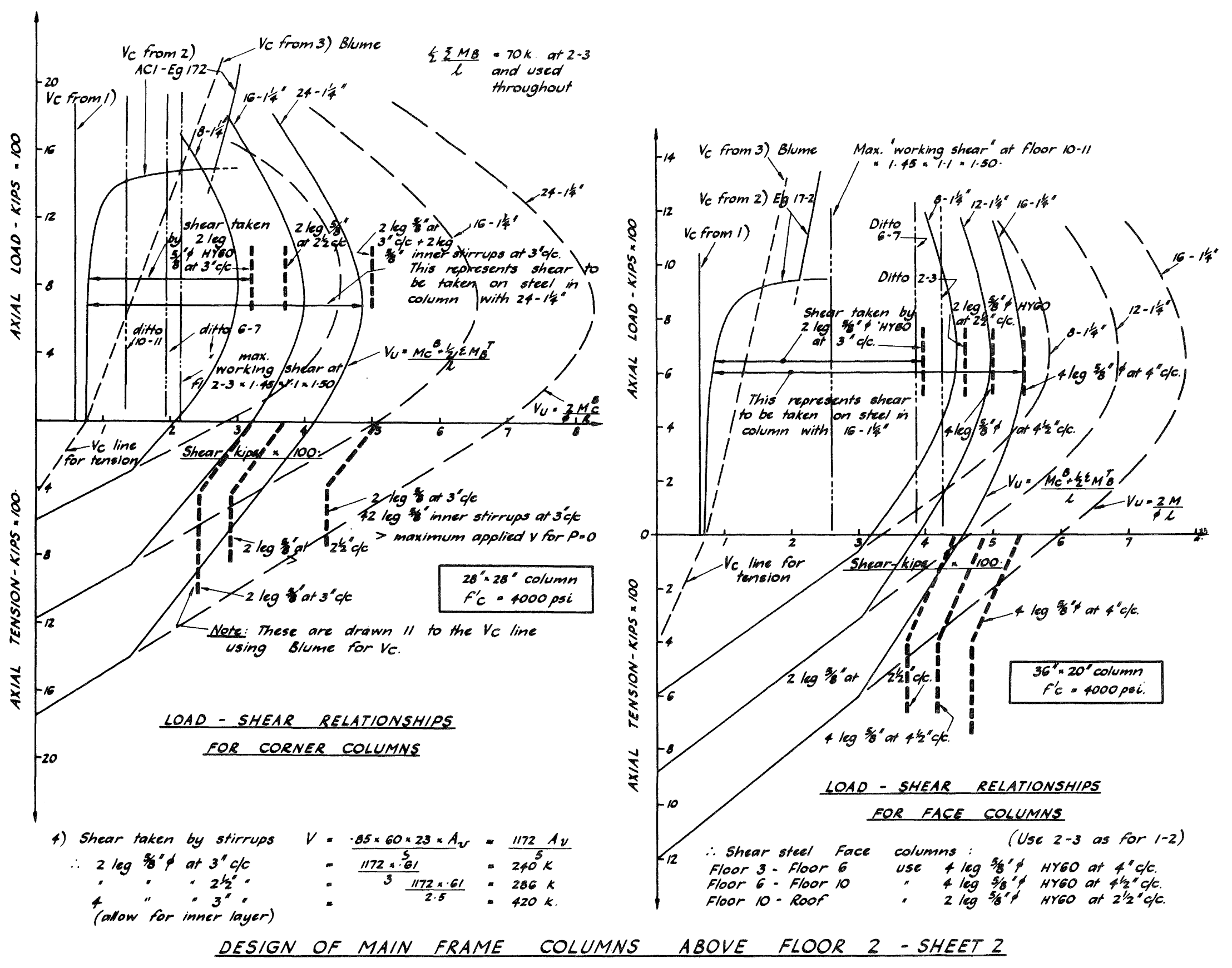




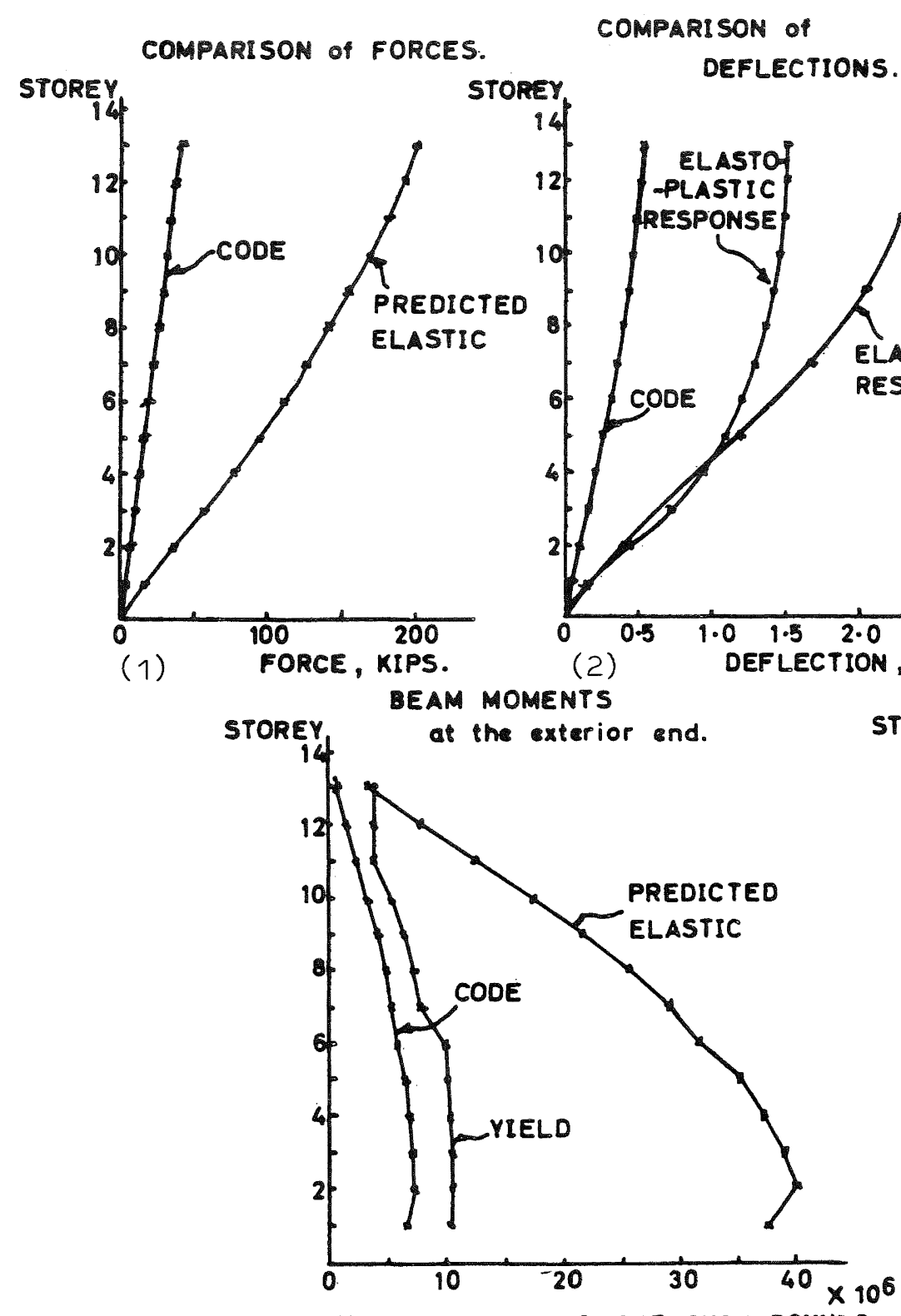

(4)
MOMENT, INCH POUNDS.

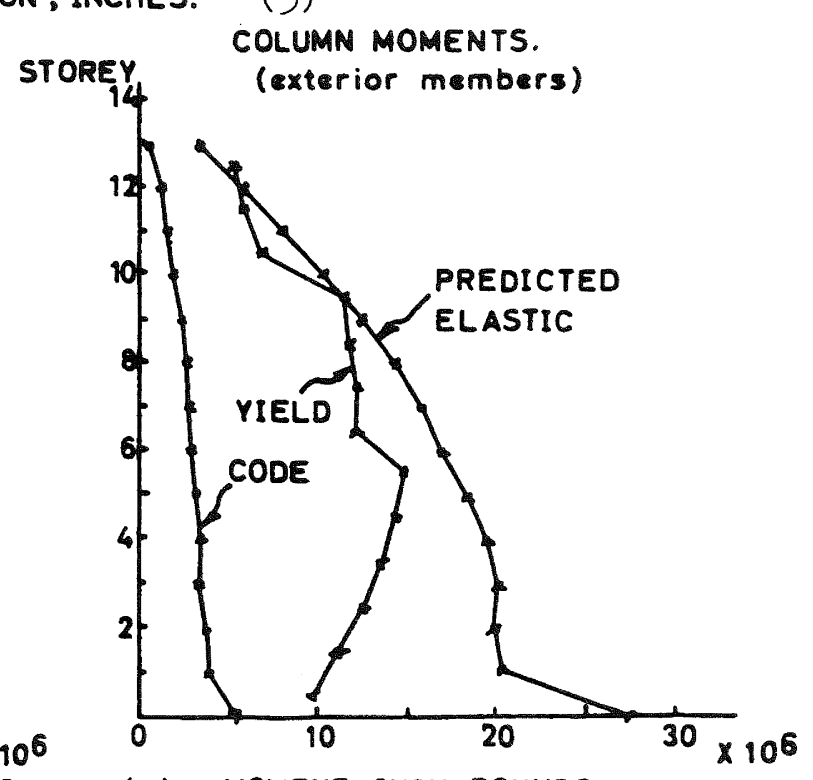

(5) MOMENT, INCH POUNDS.
DUCTILITY compared with MOMENT RATIO.

Fig. 12 Results of Elasto-Plastic Analysis.

Fig. 12 which is self-explanatory is reproduced directly from Walpole's thesis. The calculations are all based on the El Centro earthquake.

Items of interest are:

(i) Fig. 12.2 shows the deflections of the elastoplastic response to be no greater than the pure elastic response. Thus the equal energy criterion used in Fig. 10 to show the building had sufficient ductility reserves for a 1.2 times El Centro shaking is very conservative. An equal deflection criterion would give a much larger factor than 1.2. (Compare Walpole's deflection on plot of Fig. 10).

(ii) Walpole found as we had hoped that hinging did not occur in the columns and was confined to the beams. 
(iii) Fig. 12.3 shows the actual ductility demand for one set of beams. The maximum figure of 5.5 approximately is very modest when compared with the beams designed rotational capacity. The term moment ratio is the beam predicted elastic response moment over the beam yield moment capacity.

The value of this work would be enormously improved if it could be repeated using the $E 1$ Centro shaking factored by 1.5 (instead of 1.0 as in Walpole's work). A repetition using an earthquake which would excite the second or third modes would also be of value.

These exercises would show whether the columns can remain without hinges (or if hinges occur where and with what rotation) even in the most extreme conditions; a question which at the moment must continue uncertain.

\section{Some Examples of Beam and Column Detailing}

Beams Figs. 13, 14 and 15 are taken directly from the working drawings and bring out some items of interest, e.g.:

(i) Because of the close stirrup spacing it was decided that the standard stirrup hook would be impracticable and lapped anchors as in Fig. 14 were adopted throughout. The outer stirrup was also used as compression zone binding and given extra lap to suit. Spacing of stirrups was non-uniform to allow access for concrete and vibrators through the top of the beam.

(ii) The compression zone binding shown in Fig. 15 was also provided at the main steel laps. Fig. 16 shows the appearance of the bound compression zone of a typical beam as it enters a corner column.

(iii) Bond stress in beam reinforcing was a critical design factor - for this reason all beam steel was of $7 / 8$ " diameter bars placed in pairs where necessary for additional area. Special care was needed to accommodate these bars at laps (Fig. 13). The bond stress problem arose where beam bars passed through columns. With plastic hinges in the beams on each side of the column the bars are at yield in tension on one side of the column and at yield in compression on the other. This situation is difficult enough to justify even with only $7 / 8$ " diameter bars passing through a 36" wide column which in addition has special binding. In many conventional designs this type of bond condition must be a source of column splitting when eventually put to test.

At corner columns anchorage of the beam main bars also required care. Fig. 17 taken looking down the column cage on to beam bars shows how these were anchored in pairs around column bars and Fig. 18 shows how the pairs of beam bars were separated at their ends to spread the bearing stresses. 
Gridline of beam

Dimension $A$ is

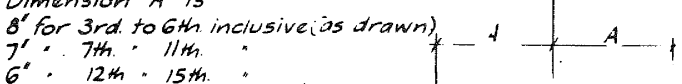

$5^{\prime \prime}$. roof balustrades(15" \& 16"

Side covers on stirrups ik".

elearance between stirrups $3^{\prime}$ each side.

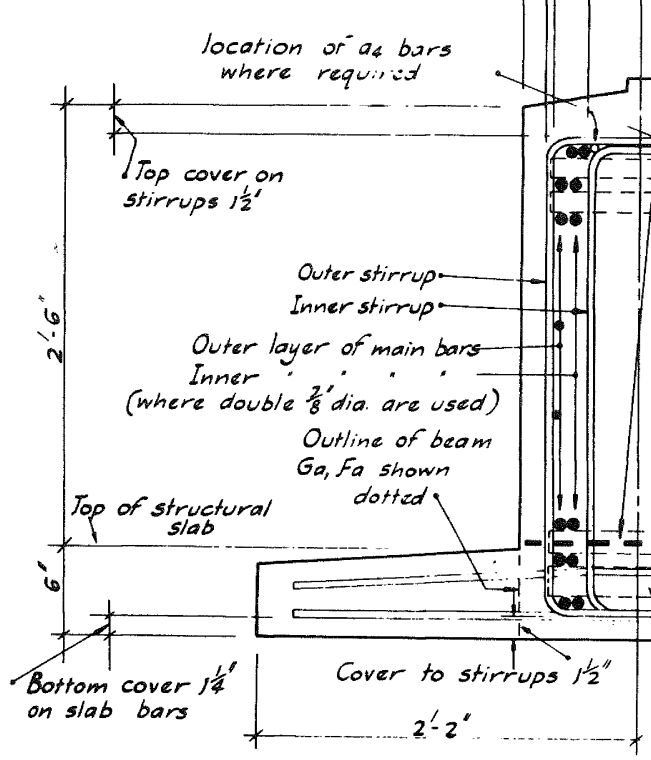

Note: Corner fillets etc. not shown

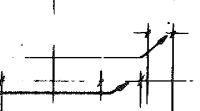

Type B stirrups not show. here-(see details above at

$$
\begin{gathered}
\text { here. elevations, wire } \\
\text { to stirrup. }
\end{gathered}
$$

\section{ALL SECTIONS EXCEPT WITHIN A'APPROX.) OF CORNER COLUMN FACE}

Fig. 13 Spandrel Beam Details.

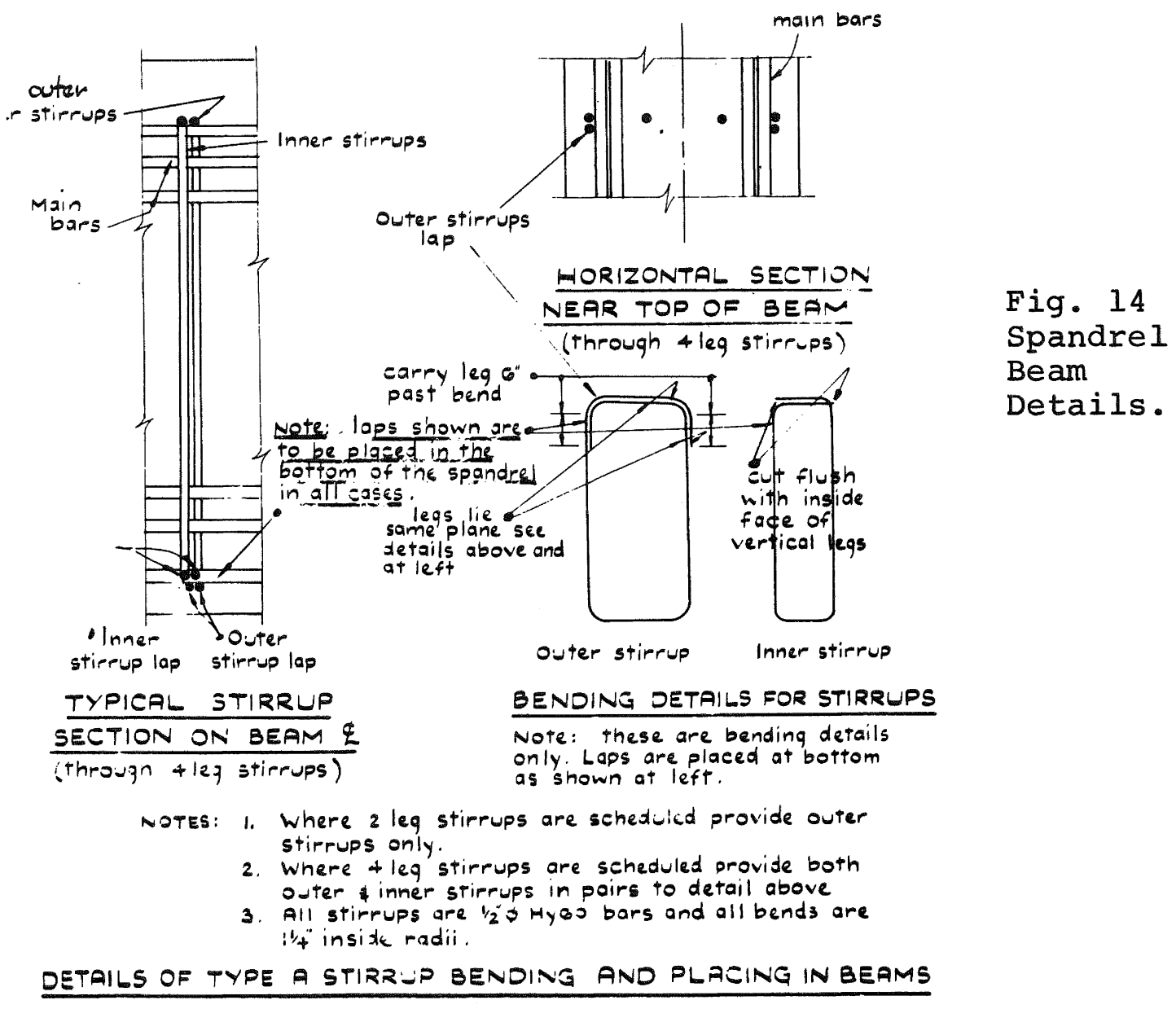




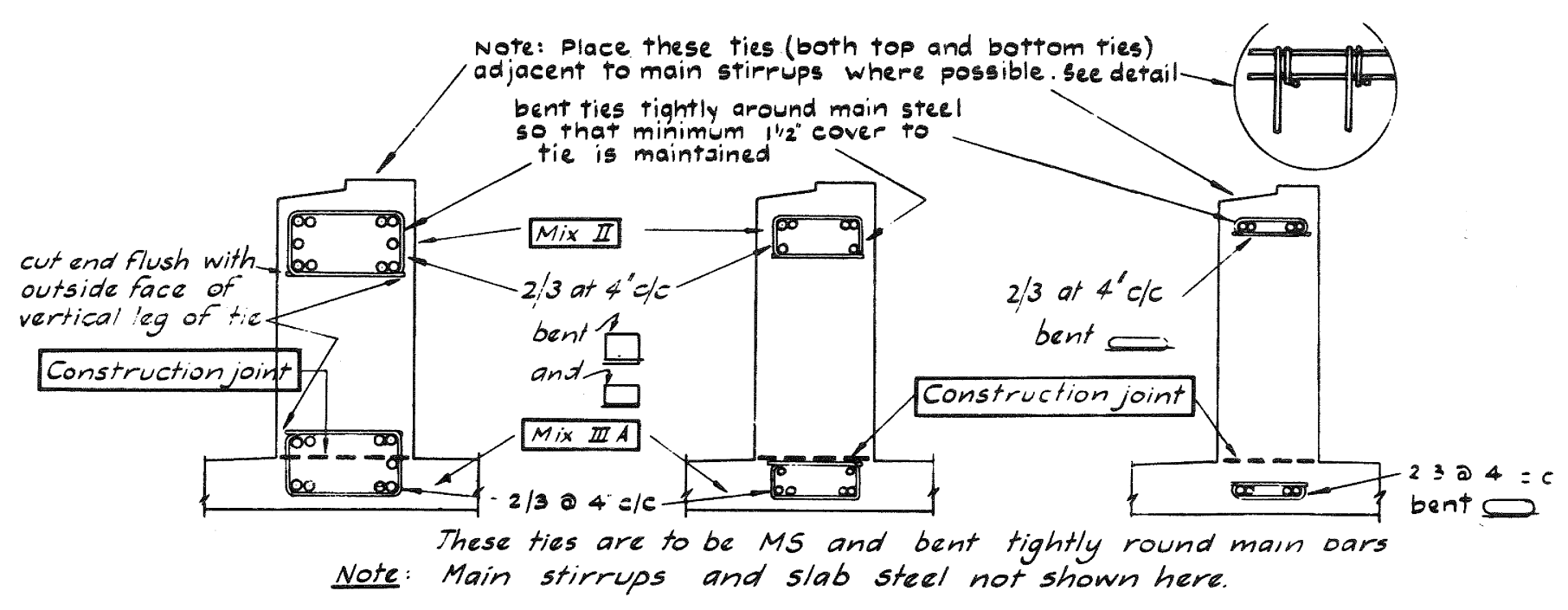

TYPE B STIRRUP DETAIL FOR 1,2 and 3 ROWS OF BARS

Fig. 15 Compression Zone Binding in Beams.

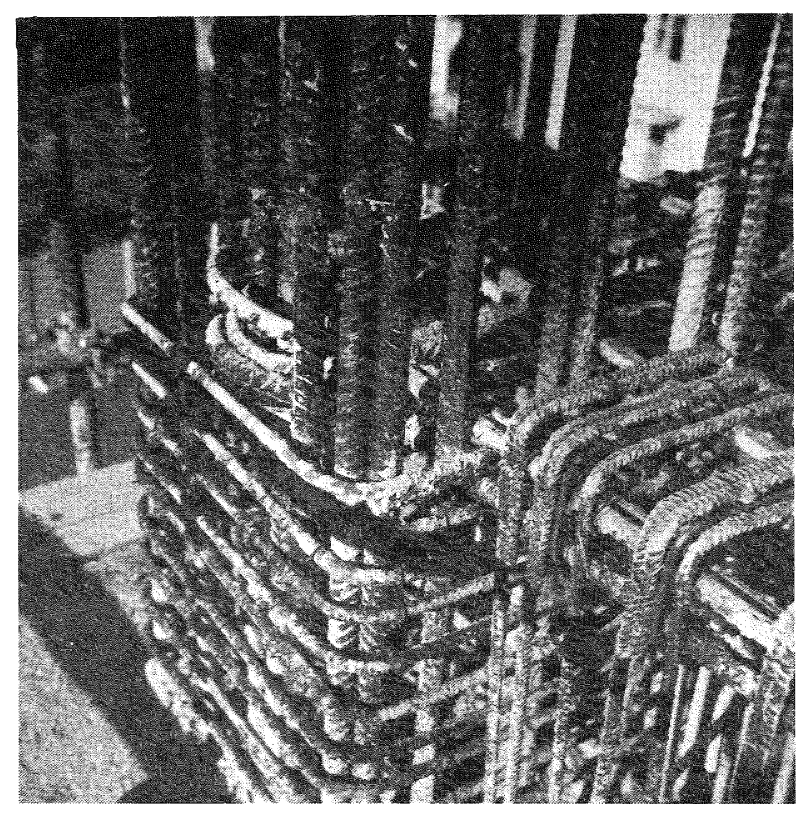

Fig. 16 Reinforcing at Beam Column Junction.

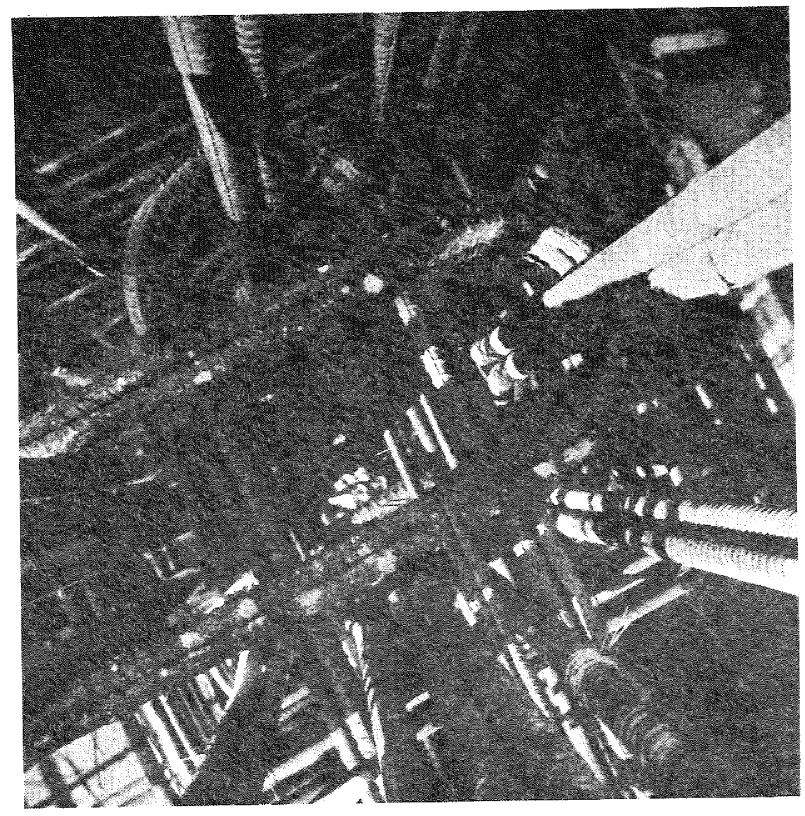

Fig. 17 Anchorage of Beam Bars Within Corner Column. 


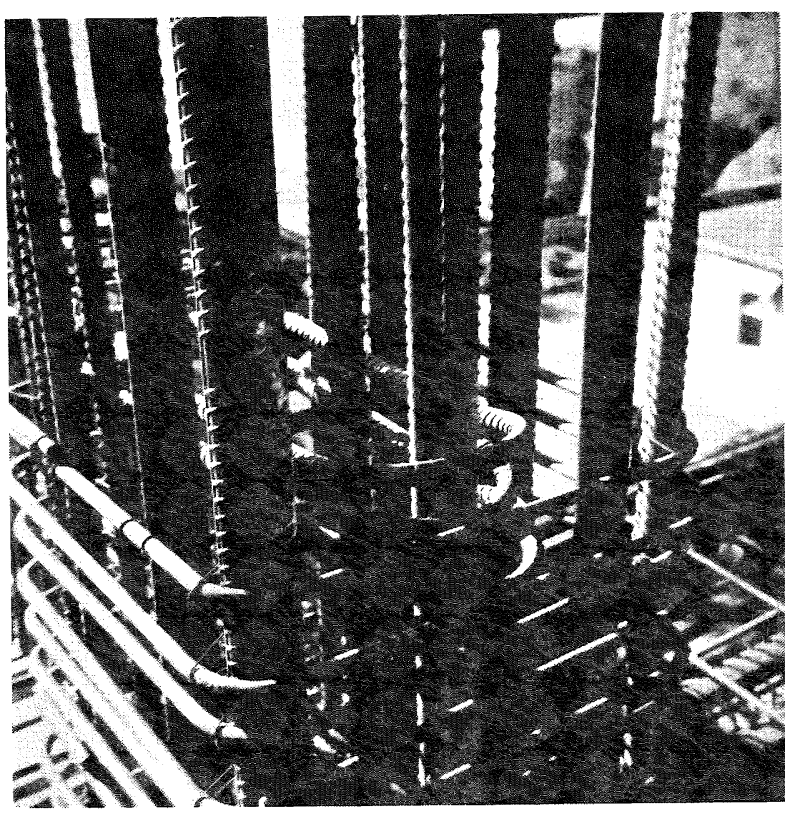

Fig. 18 Anchorage of Beams Bars Within a Corner Column.

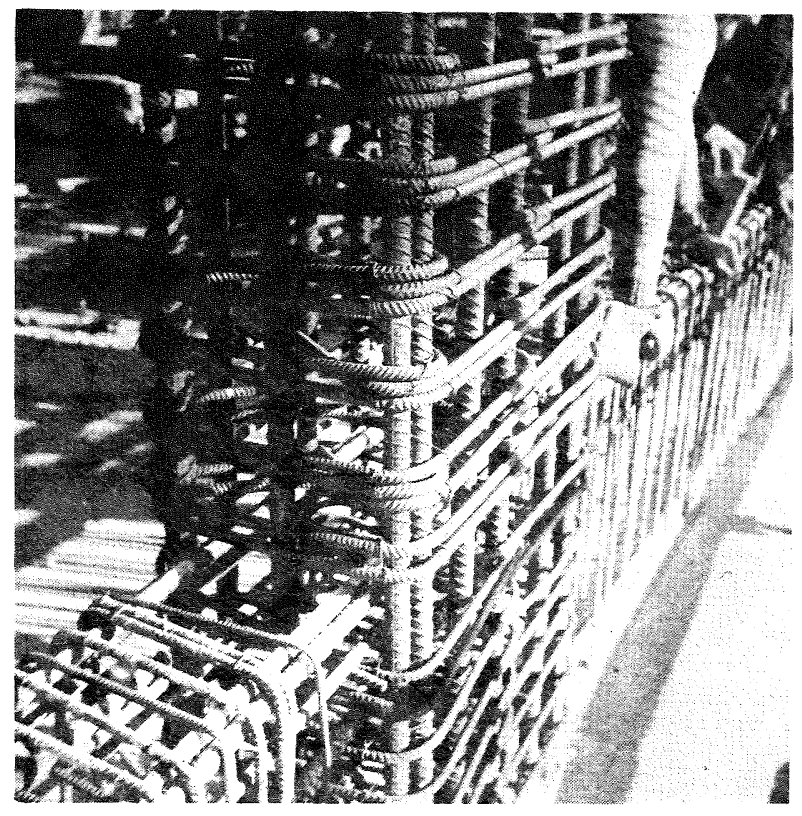

Fig. 19 Column Reinforcing.

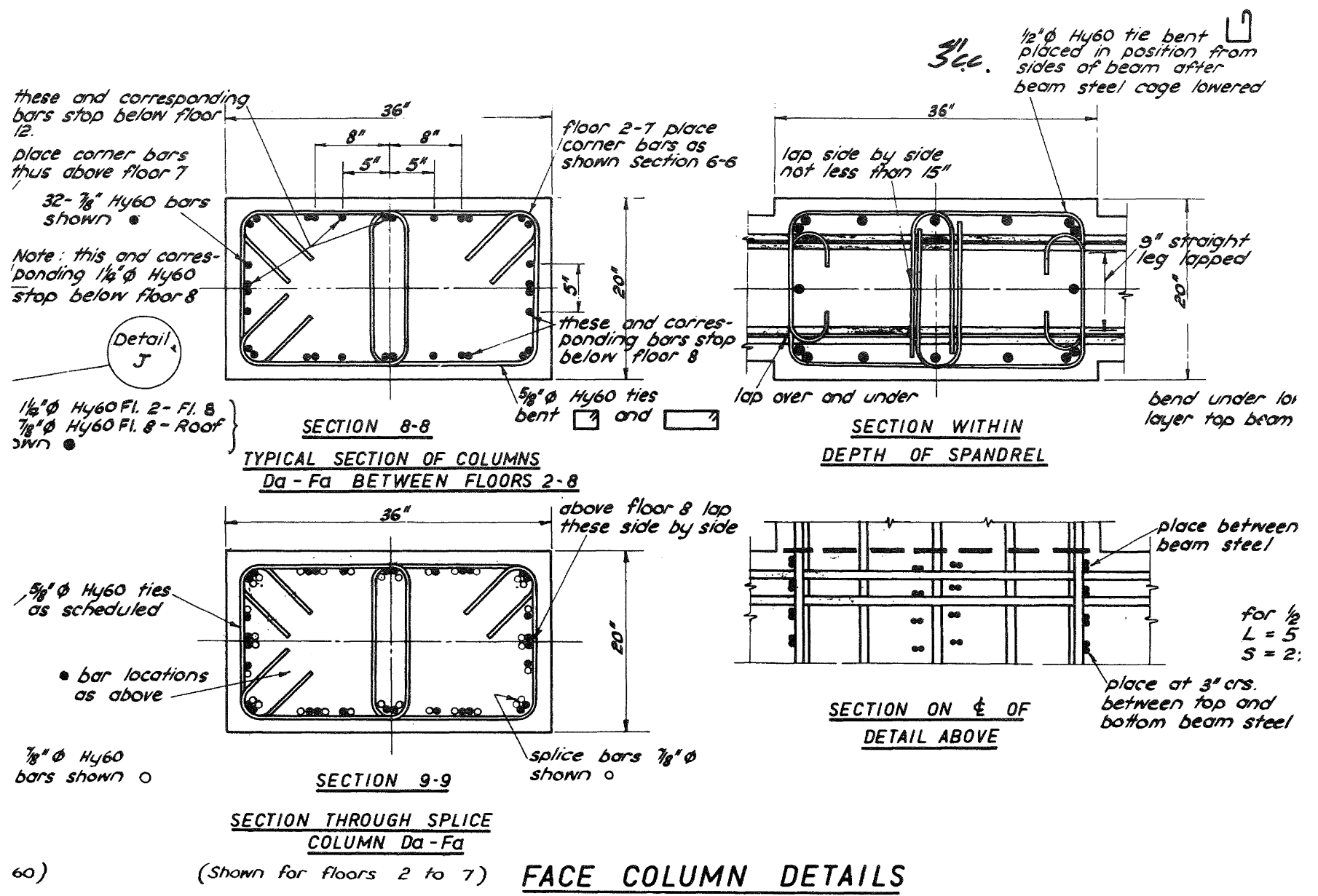

Fig. 20 
Columns To fit in the amounts of shear and binding steel described earlier as needed for the columns also required great ingenuity. Figs. 19 and 20 show how this was done for the face columns (Fig. 20 is a face column during construction) and Fig. 21 shows the same detail for corner columns. (Fig. 16 shows a corner column on site.)
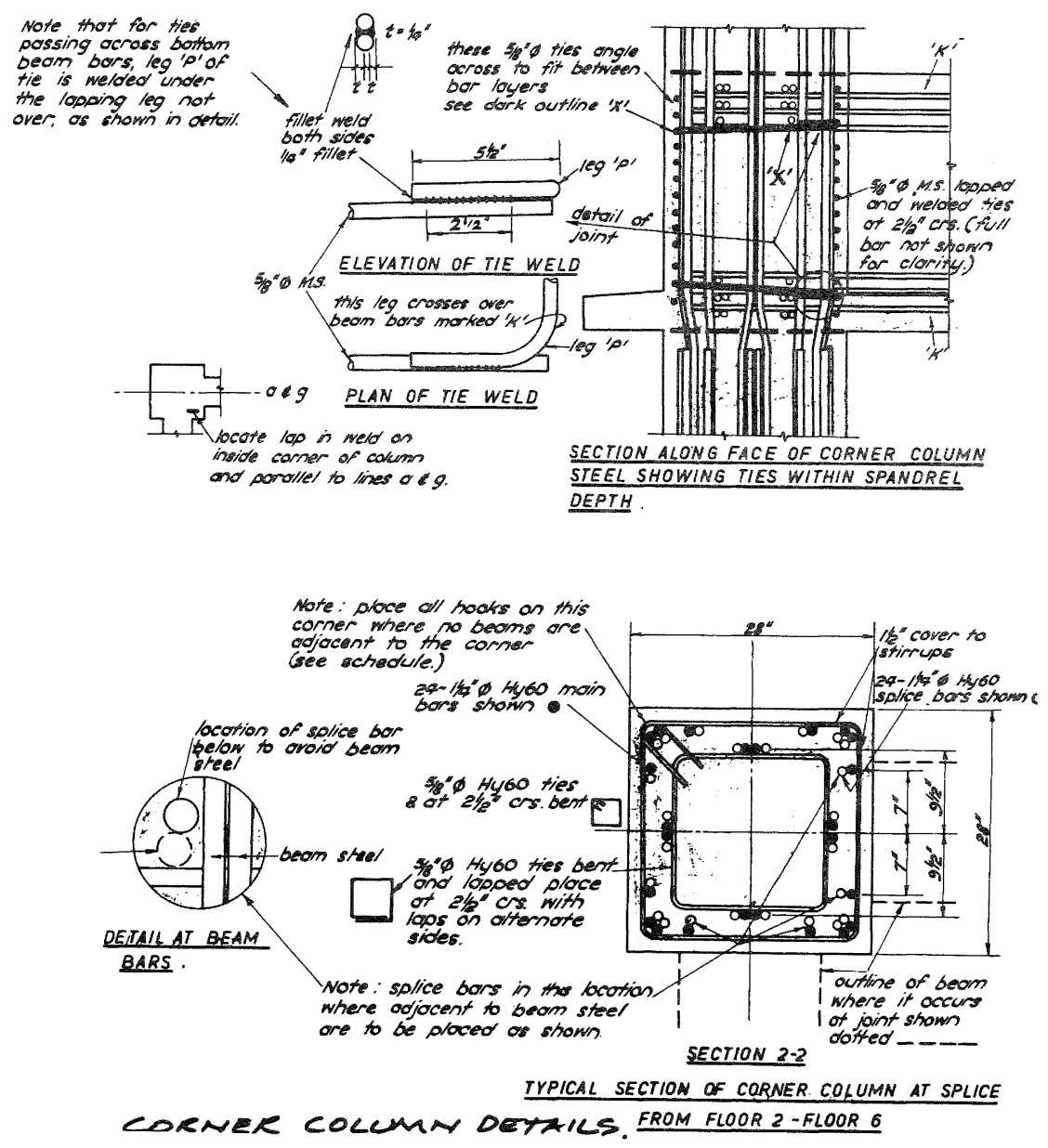

Fig. 21 Corner Column Details.

\section{Special Detailing Problems}

In my previous paper I attempted to emphasise the need for great care in designing hinges to ensure no brittle details have been left built in to the structure and showed that all sorts of devices have to be resorted to so that the design is protected. Many examples could be found from this building alone but there is space to quote only two here.

Firstly, because of the possibly large deflections of the structure when many beams develop plastic hinges in a major earthquake it was believed that the junctions of the interior columns with the flat plate 
floor slabs might fail through inability of the slabs to accept the full plastic moments of the interior columns without twisting out a piece of slab around the column in torsional shear.

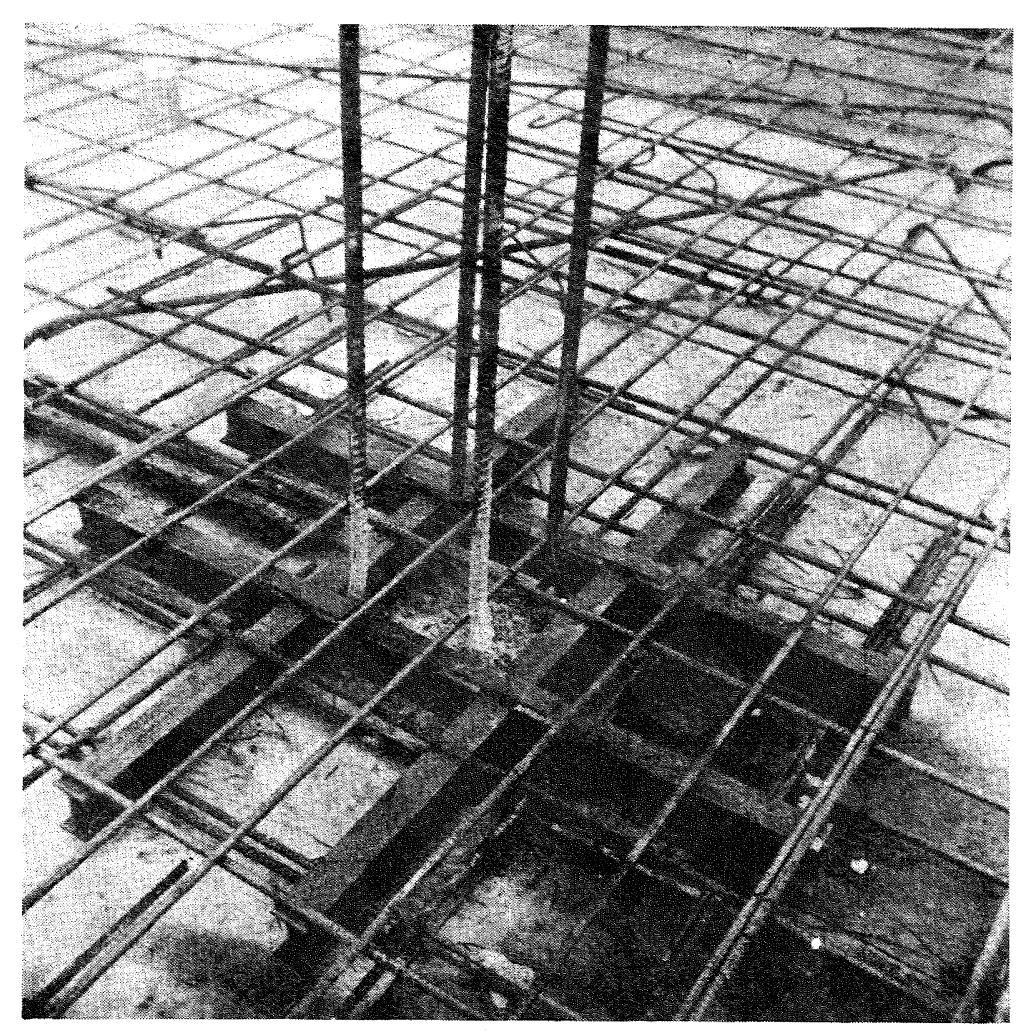

Fig. 22 Slab Shear Reinforcing at an Internal Column.

The shear reinforcing (Fig. 22) provided in the slab to resist this was extremely light by normal standards and no analytical means were available to check it reliably. Accordingly a full scale load test was done (Fig. 23). It was found that yield in the slab moment steel could be obtained without any sign of slab shear failure through several repetitions and reversals of loading. A full description of this test appears in New Zealand Engineering for August, 1967.

A second example concerns the design of the structure below second floor level. Here as is shown in Figs. 24 and 25 the layout of the structure changes from the frame structure of the upper floors to a shear wall system. In my previous paper (Vol. 2 No. 3) I explained that our knowledge of shear walls had not yet developed sufficiently to allow their use in major buildings especially in high ones. Here their use is nevertheless justified and this is done through the following argument 


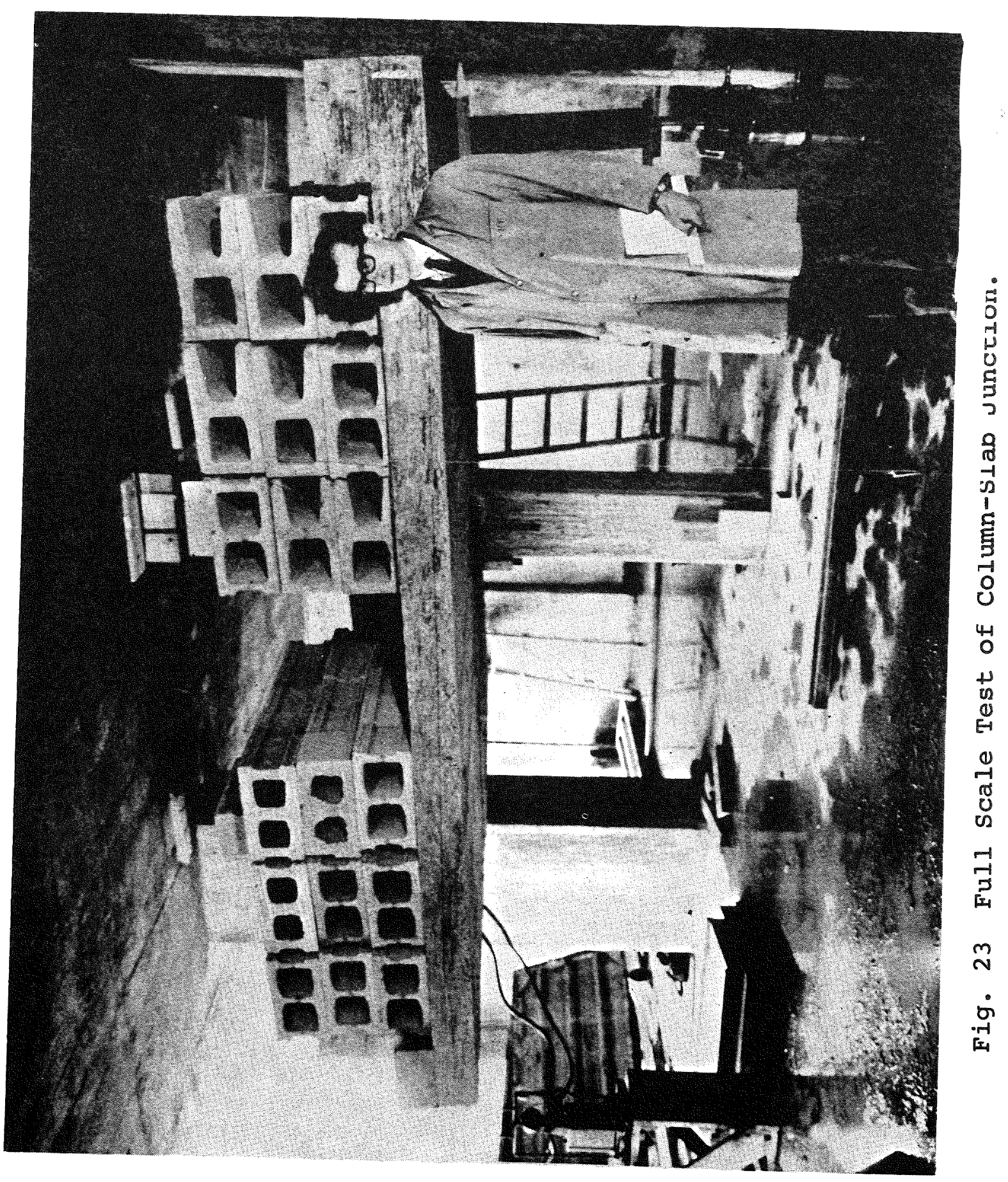




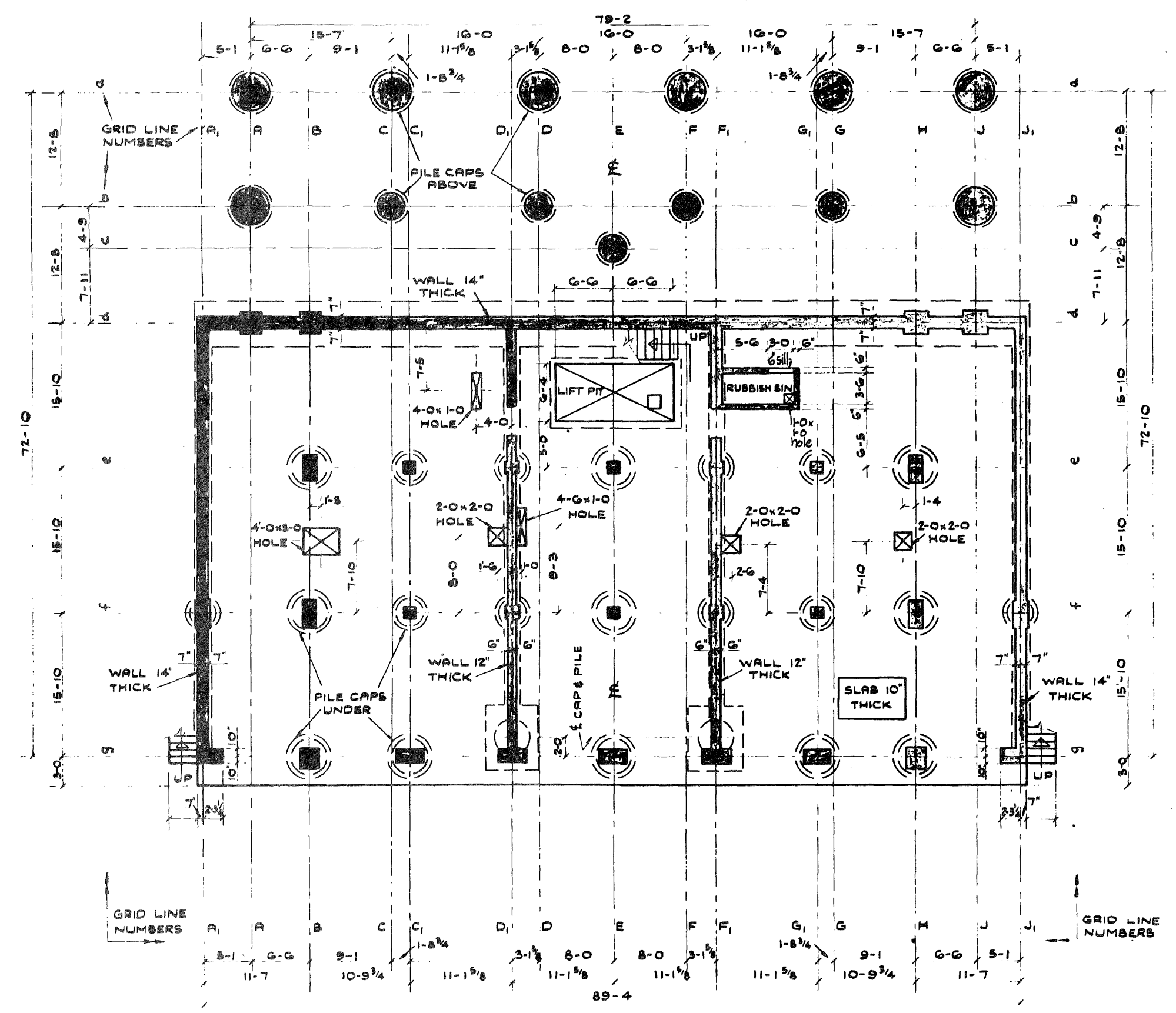




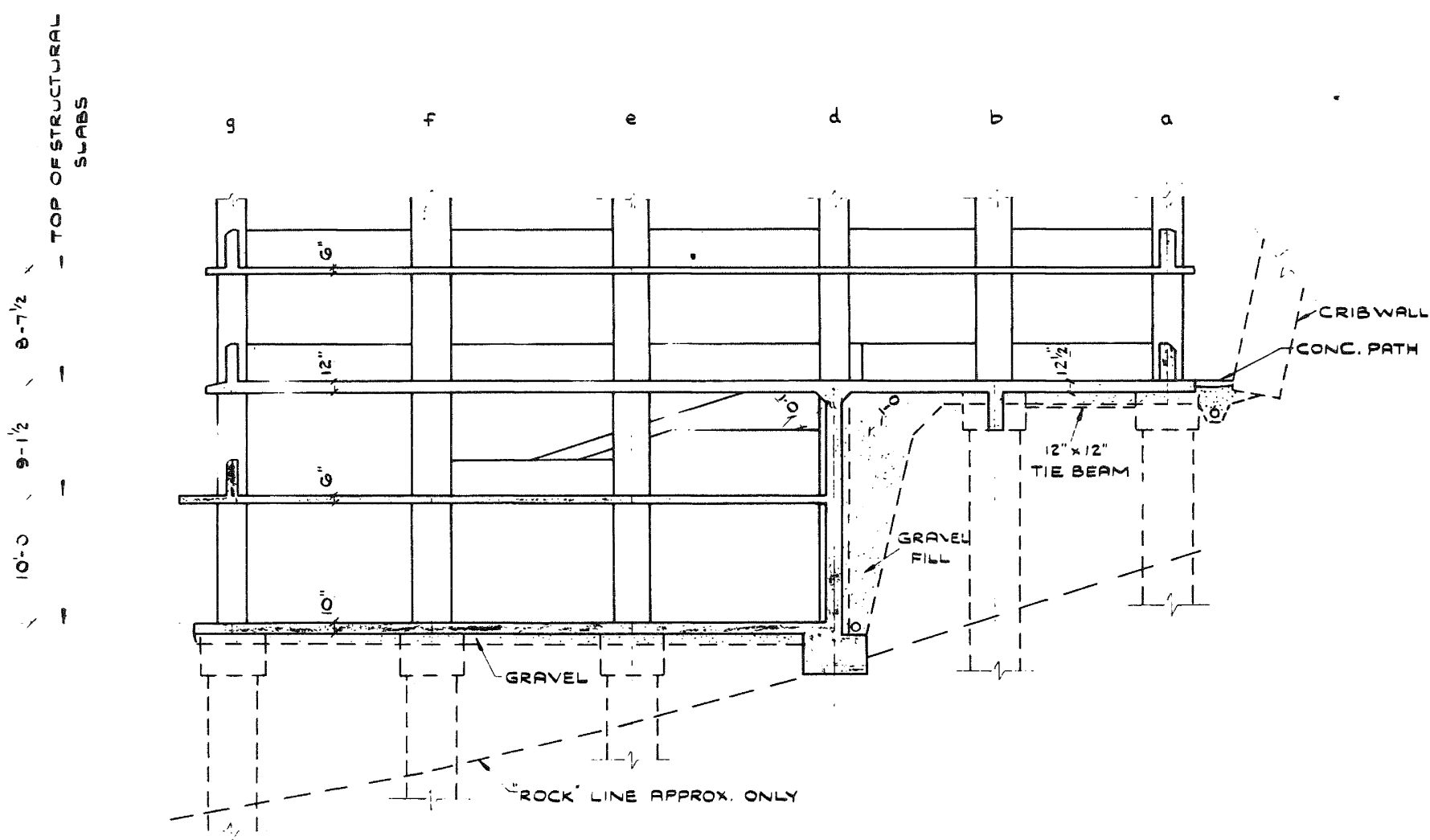

Fig. 25 Sectional Elevation Through Lower Floors.

Because the beam system of the upper floors has been carefully proportioned to give yield in nearly all the beams at approximately 1.45 times code loads this level of loads is also a quite reliable measure of the maximum value of base shear which can physically be fed into the superstructure. If then a further load factor is applied to this base shear we can obtain a set of loads to be applied to the shear wall system. If this set of loads is then followed through the detail design conscientiously we can say reliably that the shear walls will never be called on for ductile performance. In other words, it might be said that in this case the shear walls are protected from brittle failure by the "fusing" action of the beam hinges in the superstructure.

\section{Footnote:}

The paper is based on material first presented by the author in a seminar on Seismic Problems in structural Engineering held at the University of Canterbury in May 1968.

This paper refers to a previous paper by the same author published in the N.Z. Society for Earthquake Engineering Volume 2 No 3 titled "Reinforced Concrete Seismic Design". 